\title{
Vehicle automation and freeway 'pipeline' capacity in the context of legal standards of care
}

\author{
Scott Le Vine ${ }^{1,2,3}$ (D) $\cdot$ You Kong ${ }^{1} \cdot$ Xiaobo Liu $^{1} \cdot$ John Polak ${ }^{3}$
}

Published online: 20 October 2017

(C) The Author(s) 2017. This article is an open access publication

\begin{abstract}
The study evaluates, in the context of freeway segments, the interaction between automated cars' kinematic capabilities and the standard legal requirement for the operator of an automobile to not strike items that are in its path (known as the 'Assured Clear Distance Ahead' criterion). The objective is to characterize the impacts of ACDA-compliant driving behavior on the system-level indicator of roadway-network capacity. We assess the barriers to automated cars operating non-ACDA-compliant driving strategies, develop a straightforward ACDAcompliant automated-driving model to analytically estimate freeway 'pipeline' capacity, compare this behavior to human drivers, and interpret quantitative findings which are based on a range of rationally-specified parameter values and explicitly account for kinematic uncertainty. We demonstrate that automated cars pursuing ACDA-compliant driving strategies would have distinctive "fundamental diagrams" (relationships between speed and flow). Our results suggest that such automated-driving strategies (under a baseline set of assumptions) would sustain higher flow rates at free-flow speeds than human drivers, however at higher traffic volumes the rate of degradation in speed due to congestion would be steeper. ACDA-compliant automated cars also would have a higher level of maximum-achievable throughput, though the impact on maximum throughput at free-flow speed depends on the specific interpretation of ACDA. We also present a novel quantification of the tradeoff between freeway-capacity and various
\end{abstract}

Electronic supplementary material The online version of this article (doi:10.1007/s11116-017-9825-8) contains supplementary material, which is available to authorized users.

Scott Le Vine

levines@newpaltz.edu

1 School of Transportation and Logistics, and Intelligent Transportation Systems Laboratory, National United Engineering Laboratory of Integrated and Intelligent Transportation, Southwest Jiaotong University, 111 N. 1st Section, 2nd Ring Road, Chengdu 610031, People's Republic of China

2 Department of Geography, State University of New York (SUNY) at New Paltz, Hawk Drive, New Paltz, NY 12561, USA

3 Department of Civil and Environmental Engineering, Imperial College London, Exhibition Road, South Kensington SW7 2AZ, UK 
degrees of safety (one failure in 100,000 events, one failure in 1,000,000, etc.) that explicitly accounts for the irreducible uncertainty in emergency braking performance, by drawing on empirical distributions of braking distance testing. Finally, we assess the vulnerability of ACDA-compliant automated cars to lateral 'cut-ins' by vehicles making lane changes. The paper concludes with a brief discussion of policy questions and research needs.

Keywords Vehicle automation · Freeway capacity · Assured Clear Distance Ahead · Duty of care

\section{Introduction}

With the commercial rollout of increasingly-sophisticated vehicle-automation concepts, there is growing interest in the nature of potential impacts to various aspects of the transportation system, such as safety (Fagnant and Kockelman 2014; Kalra and Paddock 2016), parking (Zhang et al. 2015; Kong et al. 2016), pollutant emissions (Wadud et al. 2016), regulations (Smith 2014, Anderson et al. 2016; Gasser 2016), possible shifts from car-ownership to car-rental (Fagnant and Kockelman 2016), and how in-vehicle time is used (Malokin et al. 2015; Zmud et al. 2016).

This paper's focus relates to the impacts of highly-automated cars (cf. SAE 2014) on traffic flow on mainline freeway segments. We consider operating regimes in which the automated vehicle's (AV's) longitudinal-control system makes and then implements control decisions regarding speed and following-distance-from-forward-vehicle without input from the vehicle's occupant(s). In other words, this is a more highly automated concept than adaptive cruise control (ACC), in which a human driver makes an initial selection of speed and following distance, and the automated control system subsequently operates pursuant to this guidance. The kinematics of these two concepts are not fundamentally different, though the lack of guidance from a responsible human driver leads to distinctive issues of responsibility for vehicle operation (see "Conclusions" section).

This topic has been addressed by a number of earlier studies (cf. "Background" section); the original contributions of this research are as follows. First, 'regular' (i.e. nonemergency) freeway driving behavior is evaluated from the perspective of 'defensive driving'; we document the current legal requirements for 'defensive driving' and subsequently employ them to specify and numerically test various plausible manifestations of this general approach. Earlier work (cf. Goodall 2014) has discussed the ethical issues of programming AVs' behavior for circumstances where crashes are imminent ("crashing algorithms"); we build on prior work by Carbaugh et al. (1998) and Kanaris et al. (1997) in simulating car-following decision-making for mundane driving conditions which explicitly recognizes the potential for emergency conditions suddenly arising. Second, the kinematic parameters of the numerical analysis are derived from empirical field tests, and we take explicit account of uncertainty in braking-system performance to quantify the trade-off between crash-risk and capacity. We demonstrate that, under contemporary "Rules of the Road", faithfully replicating the behavior (see "Human drivers' degree of compliance with the ACDA Rule" section) of human drivers on a congested freeway could expose the manufacturers of automated-driving systems to a degree of liability ${ }^{1}$ that they may find

\footnotetext{
1 We note that LeValley (2013) argues that a manufacturer of highly-automated cars may be deemed to be a common carrier. Common carriers are generally required to exercise the "highest degree of care", a more stringent standard than the "ordinary or reasonable care" standard to which drivers are generally held (Blum et al. 2016).
} 
unacceptable, but reducing this risk would unavoidably reduce the capacity of the freeway network. Designers of automated control algorithms might be viewed less sympathetically than individual human drivers and be more attractive targets for litigation (as they might be seen to plausibly be able to pay out large claims for both actual as well as punitive damages).

The analysis we report in this paper is subject to several important limitations, including that the discussion of legal issues is based solely on American (U.S.) law (the consequent numerical calculations, however, are not specific to any particular jurisdiction). A second limitation is that the analysis focuses exclusively on mainline freeway segments; weaving, merging and diverging behavior are all left as topics for future research. Third, we consider only automobiles (leaving as future research needs the unique challenges posed by heavy vehicles, recreational vehicles, motorcycles, etc.) and for purposes of the numerical analysis we treat the kinematic parameters of automated cars as identical for all automated cars, whereas different manufacturers' vehicle-control systems are likely to have distinctive properties (which are not currently knowable, due to both commercial confidentiality and the expectation of technological improvement in coming years). Fourth, the numerical analysis does not explicitly take account of the effects of uncertainty in automated vehicles' sensor readings. Fifth, we focus exclusively on traffic streams of homogenous AVs; we leave issues of mixed human and AV traffic (including non-homogenous capabilities of AVs) for future research.

Throughout this paper, we employ the term 'capacity' to refer to the maximum throughput (vehicles per lane per hour) that can be sustained at a given free-flow speed. For human-driven cars, the standard model of traffic flow (TRB 2010) suggests that this value (1000 vehicles/lane/h at a 75 miles/h $[121 \mathrm{~km} / \mathrm{h}]$ free-flow speed) is much lower than typical quoted values of freeway-lane capacity, as it refers to maximum throughput at the free-flow speed, whereas typical quoted values (e.g. 2400 vehicles/h/lane, per TRB 2010) refer to maximum throughput across all speeds, which in the case of a freeway facility with a $75 \mathrm{miles} / \mathrm{h}[121 \mathrm{~km} / \mathrm{h}$ ] free-flow speed is estimated by TRB (2010) to occur at 53 miles/h $(85 \mathrm{~km} / \mathrm{h}$ ] (see "Fundamental diagram of ACDA-compliant automated car driving" section).

The remainder of this paper is organized as follows: "Background" section contains a background discussion of the relevant literature and legal standards, "Methodology" section introduces the methodology, "Results" section presents the numerical results, and "Conclusions" section concludes the paper with a summary of findings and brief discussion of research needs.

\section{Background}

A number of earlier studies have evaluated the impacts of vehicle automation on network capacity. The subsequent discussion focuses on impacts of automation on freeway-network capacity; readers interested in studies of automation on arterial networks are directed to Dresner and Stone (2008), Ferreira and d'Orey (2012), Li et al. (2014), and Le Vine et al. (2015, 2016).

The distinct concepts of connectivity (V2X communication) and automation (control by algorithm rather than human driver) are in practice closely intertwined in the literature, with various studies evaluating the interaction between them (cf. Kanaris et al. 1997; Vander Werf et al. 2002; Van Arem et al. 2006; Milanes and Shladover 2016; 
Motamedidehkordi et al. 2016; Zhou and Qu 2016; Asare and McGurrin 2016). For the purposes of this paper, however, the primary focus is on unconnected automation, in which each automated vehicle makes its own decisions on the basis of only line-of-sight information about its surroundings received from its own sensors. Whether other sources of information, specifically V2X communications, are received and disregarded (i.e. not considered trustworthy for decision-making purposes) —or simply not received —is treated as immaterial for the purposes of control decision-making. Whether AVs will be 'selfdirected' or will rely on V2X communications to 'direct their movement' is noted by Glancy et al. (2016) as a major point of uncertainty.

In order to evaluate the impacts of automation on network capacity, a necessary starting point for comparison purposes is the existing set of models of human-driving behavior (Brackstone and McDonald 1999). Noteworthy models include the 2010 Highway Capacity Manual's methodologies (hereafter referred to as "HCM-2010" (TRB 2010) and Wiedemann's models of car-following behavior (Wiedemann 1974, 1999²), which are employed in the present paper, as well as models proposed by Gipps (1981), Yang and Koutsopoulos (1996), and Fritzsche (1994). Though the HCM-2010 model is the most widely used, none of these models is uniquely correct in describing the dynamics of traffic flow with human drivers; Brackstone and McDonald (2007, p. 1183) report that "providing clear unequivocal statements regarding car following and safety levels...is still far from straightforward". Indeed, we demonstrate a wide divergence between the HCM-2010 and Wiedemann-1999 models in their analysis of human-driven traffic flow at freeway speeds (see "Fundamental diagram of ACDA-compliant automated car driving" section).

In analyzing the time gaps that human drivers leave behind the preceding vehicle, researchers have noted that humans regularly select time gaps that are much shorter than the values prescribed by standard advice (Brackstone et al. 2002; Friedrich 2016), with (Brackstone et al. 2002, p. 43) remarking that human drivers appear to "indulge in a certain amount of 'educated risk taking'". The reasons for such behavior are poorly understood; hypotheses include signaling of 'fitness' in the context of evolutionary biology (Skippon et al. 2012), or drivers simply making rational choices to accept the small risk of striking a lead vehicle in exchange for the benefit of arriving at their destination very marginally more quickly. Despite the fact that individual human drivers routinely select small time gaps that are apparently 'unsafe' when analyzed against standard kinematic criteria, and regardless of human drivers' reasons for doing so, it appears unlikely that vehicle manufacturers would do the same in the design of automated-control algorithms. The software code would leave little doubt about the decision-making logic (in contrast to acknowledged human frailties when making split-second decisions ${ }^{3}$ ), and the archived stream of information from an automated vehicle's on-board sensors would mean that the factual circumstances of a crash are also much less likely to be in dispute than in human-driver crashes for which the only evidence is physical and drivers'/eyewitnesses' memories.

\footnotetext{
2 To the authors' knowledge, there is no technical paper published by Wiedemann that documents the widely-applied "Wiedemann-1999" model; the model is described in PTV (2011).

3 Regarding acknowledgment of human frailties when making a split-second decision, Buchwalter et al. (2016 Negligence, Sect. 198) report that: “Under the common-law 'emergency doctrine,' when an actor is faced with a sudden and unexpected circumstance which leaves little or no time for thought, deliberation, or consideration, or causes the actor to be reasonably so disturbed that the actor must make a speedy decision without weighing alternative courses of conduct, the actor may not be negligent if the actions taken are reasonable and prudent in the emergency context...in certain situations, a person is not held to the strict standard of care required of a reasonably prudent person acting under ordinary circumstances.".
} 
Table 1 summarizes earlier studies that have evaluated the impacts on freeway capacity of automated vehicles operating with only line-of-sight information. Various methodologies have been employed, including both bespoke kinematic analysis and adaptation of carfollowing models of human-driving used in standard traffic-microsimulation software.

This study builds on a body of research originating in the 1990s into rear-end-collision warning and avoidance systems. Ervin et al. (1998) develop a simulation framework of adaptive cruise control (ACC) to investigate the empirical frequency of short-followingdistance episodes and either human intervention or crash occurrence. Galler and Asher (1995) similarly present a control algorithm for incorporating V2V communications in automated car-following; both Ervin and colleagues and Galler/Asher focus on safety metrics rather than capacity impacts. Farber $(1994,1995)$ reports similar studies, conducted as part of the REAMACS project. Carbaugh et al. (1998) evaluate the trade-offs between safety (defined by crash frequency and severity) and capacity on the basis of a requirement not to strike a leading vehicle. Carbaugh and colleagues evaluated kinematics in a similar manner to the present study, however they assumed emergency-braking by all vehicles at their maximum physically-achievable rate. By contrast, the present study considers a range of braking concepts for both the leading-vehicle/stationary-object (e.g. the 'weak' and 'strong' interpretations of the Assured Clear Distance Ahead doctrine described later in this section) and following vehicle (e.g. occupant-comfort considerations, at the boundary between 'normal' and 'emergency' braking, and during wet driving conditions). As with the findings reported by Kanaris et al. (1997), Carbaugh and colleagues also do not quantify the trade-off between safety and capacity in the systematic manner (in order-of-magnitude increments up to a 1 in 1,000,000 risk) of the present paper, nor do these studies address the speed-flow relationship of AVs in congested-flow conditions (i.e. the fundamental diagram of traffic flow, cf. TRB 2011).

General limitations of earlier studies are that either: (1) the requirement to avoid striking a leading vehicle or previously-obscured object is not explicitly taken into account, or (2) deceleration concepts are specified in a narrower manner than in the present paper, or (3) properties of congested-flow conditions are not addressed.

Standard advice to human drivers is to "drive defensively"; this generally includes both anticipating unexpected behavior by other drivers and selecting an appropriate following distance behind a forward vehicle, though the specific advice offered varies both qualitatively and quantitatively in terms of what is a "safe" gap. New York, for instance, advises drivers to select a two-second gap, whereas Florida advises four seconds (NYS DMV 2015; Florida DHSMV 2015). Texas also advises four seconds, and explicitly instructs motorists that "you should always be able to stop within the distance you can see ahead of your car (Texas DPS 2014, p. 48).

The Assured Clear Distance Ahead doctrine is the common law manifestation of the Defensive Driving concept; it requires a vehicle operator to "regulate his speed so that he can stop within the range of his vision" (Pearson 2005, p. 333). "Buchwalter et al. (2016, Automobiles and Highway Traffic, Sect. 1115) report that "Most jurisdictions follow the rule that a collision between a preceding and a following motorist gives rise to a

\footnotetext{
${ }^{4}$ In some jurisdictions (e.g. France, cf. Fambro et al. 1997), there are examples of the assumed emergency maneuver used by road designers being a lateral swerve (steering) rather than emergency braking. The use of such criteria is clearly inappropriate in the estimation of freeway-segment capacity, however, because on a freeway operating at capacity it cannot be assumed that suddenly maneuvering laterally into an adjacent lane can be performed without resulting in a crash.
} 
Table 1 Summary of previous studies of the impacts of unconnected vehicle automation on freeway network capacity

\begin{tabular}{|c|c|c|c|}
\hline Citation & Methodology & $\begin{array}{l}\text { Specification of parameter } \\
\text { values }\end{array}$ & $\begin{array}{l}\text { Notable findings (relating } \\
\text { to autonomous operating } \\
\text { mode) }\end{array}$ \\
\hline $\begin{array}{l}\text { Kanaris et al. } \\
\text { (1997) }\end{array}$ & $\begin{array}{l}\text { Kinematic analysis } \\
\text { (synthetic data) }\end{array}$ & $\begin{array}{l}\text { Speed: } 60 \text { miles/h (leading } \\
\text { vehicle), } 63 \text { miles/h } \\
\text { (following vehicle); } a_{l} \text { : } \\
0.8 \mathrm{~g} ; a_{f}: 0.72 \mathrm{~g} ; t_{l a g}: \\
0.5 \mathrm{~s} \text { (further } \\
\text { parameters, e.g. } \\
\text { constraints on 'jerk', can } \\
\text { be found in Kanaris } \\
\text { et al. (1997, p. 147) }\end{array}$ & $\begin{array}{l}\text { Headway between } \\
\text { automobiles of } 0.66 \mathrm{~s}\end{array}$ \\
\hline $\begin{array}{l}\text { Carbaugh et al. } \\
\text { (1998) }\end{array}$ & $\begin{array}{l}\text { Kinematic analysis } \\
\text { (empirical vehicle- } \\
\text { trajectory data) }\end{array}$ & $\begin{array}{l}\text { Latency of } 0.3 \mathrm{~s} \text { between } \\
\text { leading and following } \\
\text { vehicles braking; } \\
\text { deceleration rates per } \\
\text { empirical data } \\
\text { approximated by } \\
\text { Gaussian distribution } \\
\text { with mean } 7.01 \mathrm{~m} / \mathrm{s}^{2} \text {, } \\
\text { std.dev } 1.01 \mathrm{~m} / \mathrm{s}^{2} \text {, and } \\
\text { clipped at } 4 \mathrm{~m} / \mathrm{s}^{2} \text { and } \\
10 \mathrm{~m} / \mathrm{s}^{2}\end{array}$ & $\begin{array}{l}\text { At a flow rate of } 2500 \mathrm{veh} / \\
\text { lane/h, } 87-97 \% \\
\text { reduction in rear-end } \\
\text { crash occurrence } \\
\text { relative to human } \\
\text { drivers in } 1600 \mathrm{veh} / \mathrm{lane} / \\
\text { h conditions }\end{array}$ \\
\hline $\begin{array}{l}\text { Malone and van } \\
\text { Arem (2004) }\end{array}$ & $\begin{array}{l}\text { Traffic microsimulation } \\
\text { applying Burnham et al. } \\
\text { (1974) car-following } \\
\text { model with parameters } \\
\text { adapted to automated } \\
\text { vehicles }\end{array}$ & Time gap: $1.4 \mathrm{~s}$ & $\begin{array}{l}\text { Throughput of } 2200 \\
\text { vehicles per lane per } \\
\text { hour, where vehicles } \\
\text { operate with adaptive } \\
\text { cruise control }\end{array}$ \\
\hline $\begin{array}{l}\text { Asare and } \\
\text { McGurrin (2016) }\end{array}$ & $\begin{array}{l}\text { Traffic microsimulation, } \\
\text { applying Wiedemann- } \\
1999 \text { car-following } \\
\text { model with parameters } \\
\text { adapted to automated } \\
\text { vehicles }\end{array}$ & $\begin{array}{l}\text { Parameter descriptions } \\
\text { can be found in Asare } \\
\text { and McGurrin (2016, } \\
\text { p. } 7 \text { ) } \\
\text { Look ahead distance: } 850 \\
\text { feet; Temporary lack of } \\
\text { attention: } 0 \text { s; Number } \\
\text { of observed vehicles: } 4 \text {; } \\
\text { CC1: } 0.8 \text { s; CC2: } 11.12 \\
\text { feet; CC } 3:-6 \text { s; CC4: } \\
-0.2 \text {; CC5: } 0.2 \text {; CC6: } \\
10.44\end{array}$ & $\begin{array}{l}\text { Throughput of } \\
\text { approximately } 1800 \\
\text { 'autonomous vehicles' } \\
\text { per lane per hour }\end{array}$ \\
\hline $\begin{array}{l}\text { Motamedidehkordi } \\
\text { et al. (2016) }\end{array}$ & $\begin{array}{l}\text { Traffic microsimulation, } \\
\text { applying Wiedemann- } \\
1999 \text { car-following } \\
\text { model with parameters } \\
\text { adapted to automated } \\
\text { vehicles }\end{array}$ & $\begin{array}{l}\text { Parameter descriptions } \\
\text { can be found in } \\
\text { Motamedidehkordi et al. } \\
\text { (2016), p. 6) } \\
\text { CC0: } 1 \mathrm{~m} \text {; CC1: } 0.5 \mathrm{~s} ; \\
\text { CC2: } 4 \mathrm{~m} \text {; CC } 3:-8 \mathrm{~s} \text {; } \\
\text { CC4: }-0.1 ; \text { CC5: } 0.1 \text {; } \\
\text { CC6: } 0 ; \text { CC7: } 0.25 \mathrm{~m} / \mathrm{s}^{2} \text {; } \\
\text { CC7: } 0.25 \mathrm{~m} / \mathrm{s}^{2} ; \text { CC } 8: \\
3.5 \mathrm{~m} / \mathrm{s}^{2} ; \text { CC } 9: 1.5 \mathrm{~m} / \mathrm{s}^{2}\end{array}$ & $\begin{array}{l}\text { Mean time headway for } \\
\text { 'highly-automated } \\
\text { vehicle' of } \\
\text { approximately } 0.85 \mathrm{~s}\end{array}$ \\
\hline
\end{tabular}


Table 1 continued

\begin{tabular}{llll}
\hline Citation & Methodology & $\begin{array}{l}\text { Specification of parameter } \\
\text { values }\end{array}$ & $\begin{array}{l}\text { Notable findings (relating } \\
\text { to autonomous operating } \\
\text { mode) }\end{array}$ \\
\hline Friedrich (2016) & $\begin{array}{l}\text { Minimum headway } \\
\text { calculated on basis of } \\
\text { speed, vehicle length, } \\
\text { minimum 'safety } \\
\text { distance to vehicle } \\
\text { ahead', and time gap }\end{array}$ & $\begin{array}{c}\text { Speed: } 70 \mathrm{~km} / \mathrm{h} \text {; vehicle } \\
\text { length: } 4.5 \mathrm{~m} \text {; minimum } \\
\text { safety distance: } 3 \mathrm{~m} ; \\
\text { Time gap: } 0.5 \mathrm{~s}\end{array}$ & $\begin{array}{l}\text { Capacity per lane of } 3900 \\
\text { automobiles per hour } \\
\text { with "purely } \\
\text { autonomous traffic" (p. } \\
326)\end{array}$ \\
\hline
\end{tabular}

presumption of negligence on the part of the following motorist, whether the preceding vehicle is moving, stopped, or stopping."

The Sudden Emergency doctrine qualifies the ACDA criterion; Sudden Emergency generally excuses a driver from negligence in the case of striking a vehicle, object, or person which has unexpectedly and suddenly moved laterally or vertically ${ }^{5}$ into their trajectory (Pearson 2005). For instance, "A motorist driving at a reasonable speed and obeying the rules of the road is generally not liable for injuries to a child who darts in front of the vehicle so suddenly that the motorist cannot avoid injuring the child, as where a child darts out from behind other vehicles that were stopped in traffic, directly into the path of the vehicle, and there was no evidence that [the] driver was driving too fast" (Buchwalter et al. 2016, Automobiles and Highway Traffic, Sect. 498). Similar logic has been found applicable in the circumstance of one vehicle abruptly changing lanes to place itself directly in front of another vehicle's trajectory (Decker v. Wofford 1960), though the presence of stationary and reasonably expected road features (e.g. the crest of a hill limiting sight lines) has been held to not warrant application of the Sudden Emergency exception (Coppola v. Jameson 1972).

Glancy et al. (2016) posit that AV manufacturers may face "design-defect claims in which a particular programming choice associated with an accident is attacked as defective" (p. 39). Though ACDA is the generally-applied standard relevant to longitudinal vehicle control by human drivers, in practice it raises three major pragmatic issues relating to automated operation.

The first of these issues is that, notwithstanding their obligations under the ACDA rule, human drivers routinely violate it in the exercise of normal driving behavior. Leibowitz et al. (1998) document, for instance, that strict adherence to the ACDA criterion would require human drivers of automobiles to travel no faster than approximately $20 \mathrm{miles} / \mathrm{h}$ $(32 \mathrm{~km} / \mathrm{h}$ ) at nighttime on unlighted roads (regardless of roadway functional class), in order to be able to stop in time to avoid a 'dark-clad pedestrian'. Despite traffic speeds at night exceeding $20 \mathrm{miles} / \mathrm{h}(32 \mathrm{~km} / \mathrm{h})$ on much of the unlighted road network, as well as posted speed limits far in excess of this speed, courts have attributed negligence to drivers not observing the ACDA rule at nighttime (cf. Mantz v. Continental Western Insurance Company 1988; Dranzo v. Winterhalter 1990). A fundamental tension arises from the fact that holding automated vehicles to the ACDA standard at all times could result in driving that is more conservative than human driving, which would tend to reduce capacity.

\footnotetext{
5 Buchwalter et al. (2016 Automobiles and Highway Traffic, Sect. 487) report that: "A motorist who is proceeding along a highway where children are playing on plots of grass bordering it is under no duty to anticipate children dropping from trees.".
} 
The second issue is that ACDA generally requires vehicle operators to avoid colliding with both the vehicle ahead (the 'weak' ACDA interpretation) as well as stationary objects (the 'strong' ACDA interpretation). If the following vehicle strictly observes the ACDA requirement to be able to "stop within the range of his vision", the vehicle must avoid striking a possible stationary object ${ }^{6}$ in the travel lane (e.g. a moderate-sized piece of road debris) which only becomes 'within the range of his vision' once the leading vehicle (which blocks the forward line of sight) has passed over the foreign object. We show (see "Results" section) that imposing this 'requirement on AVs would result in large decreases of roadway capacity as measured by vehicles-per-lane-per-hour.

The third pragmatic issue with rigid application of ACDA is that, even in cases where striking an object would not be negligent, the manufacturer may nevertheless wish to instruct the vehicle to drive more conservatively than the minimum legal standard. The designer may, for instance, plausibly view a heightened degree of occupant-safety as a marketing advantage. Under current law, the only apparent limitation to conservative driving behavior in most jurisdictions are statutes that prohibit 'impeding' the flow of traffic, and that such laws typically provide explicit exemption for slowing "when necessary for safe operation" (New York Vehicle and Traffic Law, Section 1181; cf. also California Vehicle Code Section, 22400a).

While courts have generally held that the operator of an automobile following another vehicle "must handle the automobile in recognition of the superior rights of the traveler in front" (Naffky 2012, Sect. 734), the operator of the following vehicle "may assume that the preceding vehicle is being driven with care and caution, will use every precaution to avoid being struck in the rear by following vehicles, [and] will give timely warning, by an appropriate signal, of his or her purpose to stop, or decrease the speed of the car, or to turn" (Naffky 2012, Sect. 735). The obligation of the leading vehicle to signal when turning or braking has historically referred to visual indications, but may in the future be broadened to include electronic V2X messaging. In the case of visual turning/braking indicators, the leading vehicle's operator generally bears responsibility for signaling their maneuver (Naffky 2012, Sect. 698), rather than whether the following vehicle's operator receives and processes the signal correctly (Naffky 2012, Sect. 703). This is a minor distinction in the case of plainly-visible visual indicators (brake lights and turn signals), however in the case of V2X electronic messaging there is the novel possibility of data packets being successfully transmitted by the leading vehicle but failing to be received by the following vehicle (Bergenhem et al. 2014). A following vehicle would also quite reasonably place superior trust in the condition of its own sensing/processing equipment in comparison to the sensing/processing/V2V-signaling equipment of other vehicles on the road. ${ }^{7}$ Whilst the forward driver owes a duty of care to the following vehicle (Naffky 2012, Sect. 734), the following vehicle's lack of visibility beyond the vehicle ahead prevents it from knowing whether circumstances ahead of the forward vehicle have presented a sudden emergency that requires the forward vehicle to brake. Given that there is very little private benefit (in

\footnotetext{
${ }^{6}$ In Louisiana Farm Bureau Mutual Insurance v. Dunn (1986), for instance, the defendant was found negligent for having driven into a herd of cows that were standing on a state highway. However, the requirement to be able to stop for an unexpected stationary object is a very restrictive interpretation of ACDA and has not always been applied. Naffky (2012, Sect. 664) reports, for instance, that "A driver is not obligated to anticipate a body lying in the roadway, in the direct path of his vehicle; such an event constitutes a classic emergency situation, implicating the emergency doctrine."

7 The unique liability challenges posed by automated vehicle operating in platoons and other non-ACDAcompliant driving behavior that requires 'trusting' V2X messaging have been recognized for many years (cf. Euler 1990; IVHS America 1992; Khasnabis et al. 1997; Kalra et al. 2009).
} 
terms of travel time savings) to the occupants of a following vehicle from following closely behind the leading vehicle and potentially large costs (in the form of crash risk for which some combination of the following vehicle's manufacturer and/or occupant would be liable), it appears prudent, under prevailing technology and rules of the road, for vehicles in a traffic stream to make control decisions on the basis of information from their own line-of-sight sensing.

\section{Methodology}

The numerical analysis of this study subsequently implemented ACDA-compliant driving behavior via a kinematic model. We then perform comparisons with capacity values calculated from the HCM-2010 (TRB 2010) and Wiedemann-1999 (PTV 2011) models of human driving behavior, and also draw on empirical "Naturalistic Driving" data from two sources (TRB 2013; USDOT 2016) to characterize additional dimensions of humandriving behavior. These tasks are described in this section.

Equations 1 and 2 present the minimum requirement for ACDA-compliant driving behavior, based on the fundamental equations of motion. Equations 1 and 2 are expressed in terms of headway (the time gap between the front of the leading vehicle and the following vehicle) and following distance, respectively:

$$
\begin{gathered}
H_{\text {min }}=t_{\text {lag } f}+\frac{v}{2 * a_{f}^{-}}+\frac{x_{v e h}-\frac{v^{2}}{2 * a_{l}^{-}}}{v} \\
x_{\text {min }}=v * t_{\text {lag } f}+\frac{v^{2}}{2 * a_{f}^{-}}-\frac{v^{2}}{2 * a_{l}^{-}}+x_{v e h} \\
C_{v}=\frac{1}{H_{\text {min }}}
\end{gathered}
$$

Notation is described in Table 2; the derivation of Eqs. 1 and 2 can be found in the Appendix of Le Vine et al. (2016). Capacity $\left(C_{v}\right)$ at free-flow speed $v$ is the maximum throughput of vehicles at the specified speed; it is calculated by taking the reciprocal of the minimum headway value.

We note that a single value of velocity is specified for both $v e h_{l}$ and $v e h_{f}$ (a pair of leading and following vehicles) to represent both vehicles having the same initial speed under conditions of uncongested flow. Separate notation $\left(a_{l}^{-}\right.$and $\left.a_{f}^{-}\right)$is shown, however, for the rates of deceleration. These are the rates of deceleration that would govern in case of $v e h_{l}$ initiating emergency braking without advance warning and $v e h_{f}$ responding by also braking. We present results under various assumptions for $a_{l}^{-}$and $a_{f}^{-}$.

The sources of empirical parameter values for automated vehicles are presented in Table 3. A particularly important assumption is the value of $t_{\text {lag. }}$ : the maximum possible amount of elapsed time that $v e h_{f}$ assumes can take place between $v e h_{l}$ and $v e h_{f}$ initiating emergency braking. Shladover (1997) points out that it is "very difficult" (p. 14) to select uniquely correct values for $t_{\text {lag.f }}$, with (Bierstedt et al. 2014, p. 22) noting that "the exact operating characteristics of automated vehicle technologies are proprietary and unknown". This is due to multiple interacting factors including commercial sensitivity on the part of automotive manufacturers, and improvement over time in sensing/processing/actuating capabilities. For the purposes of this study, we generally specify $t_{\text {lag.f }}$ to be $0.4 \mathrm{~s}$, though 
Table 2 Summary of notation. Adapted from Le Vine et al. (2016)

\begin{tabular}{ll}
\hline Notation & Description \\
\hline$v e h_{l}, v e h_{f}$ & $\begin{array}{l}v e h_{l} \text { and } v e h_{f} \text { denote the leading and following vehicles, respectively } \\
H_{\text {min }}, x_{\text {min }}\end{array}$ \\
$\begin{array}{l}H_{\text {min }} \text { is the minimum headway (in units of time) between the rear bumpers of } v e h_{l} \\
\text { and } v e h_{f} \text { that is consistent with the ACDA criterion. } x_{\text {min }} \text { is identical, but denotes } \\
\text { spacing (units of distance) rather than time }\end{array}$ \\
$\begin{array}{l}\text { Length (units of distance) of } v e h_{l} \\
x_{v e h}\end{array}$ \\
$\begin{array}{l}\text { Free-flow speed of the traffic stream (assumed, without loss of generality, to be } \\
\text { equal for } v e h_{l} \text { and } v e h_{f} \text { ) }\end{array}$ \\
$\begin{array}{l}a_{l}^{-} \text {and } a_{f}^{-} \text {denote the maximum rate of deceleration of } v e h_{l} \text { and } v e h_{f}, \text { respectively } \\
a_{l}^{-}, a_{f}^{-}\end{array}$ \\
$\begin{array}{l}\text { Maximum duration of time that the controller of } v e h_{f} \text { is prepared to assume can } \\
\text { elapse between } v e h_{l} \text { commencing emergency braking and } v e h_{f} \text { subsequently } \\
\text { initiating emergency braking }\end{array}$ \\
\hline
\end{tabular}

we test (in Scenario \#8) the effect of an arbitrarily-small latency value. The specification of $0.4 \mathrm{~s}$ is greater than the $0.2 \mathrm{~s}$ of latency described in Anderson et al. (2013), which is predicated on ideal lighting and weather conditions; we selected a larger value in order to account for the fact that an automated vehicle cannot know in advance with certainty whether or not lighting and environmental conditions will be optimal at the moment that circumstances abruptly change and emergency braking is required. A conservative amount of processing time also enables multiple sensor observations to be processed before initiating emergency braking. Limit false positives is an important consideration, particularly if the specified deceleration rate of emergency braking is sharp enough to be uncomfortable or dangerous for the AV's unsuspecting occupants (e.g. if the deceleration could cause a hot beverage in the AV to spill onto an occupant).

We employ VISSIM software (PTV 2011) to implement the Wiedemann-1999 carfollowing model which we use (in addition to HCM-2010) as a descriptor of humans' driving behavior on freeways. Where we report results from the Wiedemann-1999 model, they are on the basis of a 60-min analysis period, which is preceded by a 15-min 'warm-up' period. The network consisted of a single-lane freeway-class road segment five $\mathrm{km} \mathrm{(3 \textrm {mi } )}$ in length, with $0 \%$ grade and no horizontal or vertical curves. All vehicles were defined to be 'cars', with identical 'desired speeds'. Demand was specified (at $3000 \mathrm{veh} / \mathrm{h}$ ) to be

Table 3 Values specified for each operational parameter for automated vehicle control

\begin{tabular}{|c|c|c|}
\hline Parameter & $\begin{array}{l}\text { Value (employed in all scenarios } \\
\text { except where otherwise indicated) }\end{array}$ & Notes \\
\hline$x_{\text {veh }}$ & 19 feet $(5.8 \mathrm{~m})$ & $\begin{array}{l}19 \text { feet }(5.8 \mathrm{~m}) \text { is the standard length of 'passenger car' } \\
\text { design vehicle, per (AASHTO 2011) }\end{array}$ \\
\hline$a_{f}^{-}$ & $16.4 \mathrm{ft} / \mathrm{s}^{2}\left(5.0 \mathrm{~m} / \mathrm{s}^{2}\right)$ & See discussion in "Specification of scenarios" section \\
\hline$a_{l}^{-}$ & $28.3 \mathrm{ft} / \mathrm{s}^{2}\left(8.6 \mathrm{~m} / \mathrm{s}^{2}\right)$ & See discussion in "Specification of scenarios" section \\
\hline$t_{\text {lag } f}$ & $0.4 \mathrm{~s}$ & $\begin{array}{l}\text { See discussion in "Specification of scenarios" } \\
\text { section. Note that low-latency assumptions (e.g. } 0.2 \mathrm{~s} \text { ) } \\
\text { are predicated on ideal conditions of good lighting, } \\
\text { fair weather and } 0 \% \text { failure rates in sensing/control } \\
\text { (Anderson et al. 2013) }\end{array}$ \\
\hline$v$ & Varies & $\begin{array}{l}\text { Results are reported for values of velocity between } 1 \\
\text { and } 100 \text { miles } / \mathrm{h}(161 \mathrm{~km} / \mathrm{h})\end{array}$ \\
\hline
\end{tabular}


comfortably in excess of capacity for human drivers; capacity conditional on speed was calculated by measuring achieved flow for different 'desired speeds'. The numerical results we present are averages across ten simulation runs for each desired speed.

\section{Specification of scenarios}

The analysis we present in "Results" section is based on a set of 11 scenarios, to account for uncertainties in AVs' prospective operational regimes. The scenarios were selected to expose various properties of the simulation system, and are intended to be representative rather than exhaustive.

In the Baseline 'Weak' Scenario, $a_{l}^{-}$and $a_{f}^{-}$are specified to be $-28.3 \mathrm{ft} / \mathrm{s}^{2}\left(8.6 \mathrm{~m} / \mathrm{s}^{2}\right)$ and $-16.4 \mathrm{ft} / \mathrm{s}^{2}\left(5.0 \mathrm{~m} / \mathrm{s}^{2}\right)$, respectively. This represents the 'weak' interpretation of the ACDA rule (as do all Scenarios other than the Baseline 'Strong' Scenario). $-28.3 \mathrm{ft} / \mathrm{s}^{2}$ $\left(8.6 \mathrm{~m} / \mathrm{s}^{2}\right)$ is the maximum observed sustained rate of human-driver deceleration of passenger cars on dry pavement reported in (Fambro et al. 1997). $-16.4\left(0.5 \mathrm{~g} ; 5.0 \mathrm{~m} / \mathrm{s}^{2}\right)$ is both the upper limit of deceleration permitted for "Full Speed Range Adaptive Cruise Control Systems" and the lower limit of required deceleration of "Forward Vehicle Collision Mitigation Systems", as specified by the International Standards Organization's (ISO) Standards \#22179 and \#22839 (ISO 2009, 2013). In other words, - $16.4 \mathrm{ft} / \mathrm{s}^{2}$ $\left(5.0 \mathrm{~m} / \mathrm{s}^{2}\right)$ is a reasonable breakpoint between 'normal' and 'emergency' deceleration. These values ( -28.3 and $-16.4 \mathrm{ft} / \mathrm{s}^{2}\left[8.6\right.$ and $\left.5.0 \mathrm{~m} / \mathrm{s}^{2}\right]$ for $a_{l}^{-}$and $a_{f}^{-}$, respectively) were previously used as the 'Baseline' scenario in the companion study of AVs' queue discharge at signalized intersections (Le Vine et al. 2016).

The Baseline 'Strong' Scenario represents the 'strong' interpretation of the ACDA rule: $v e h_{f}$ selects its gap for following $v e h_{l}$ such that it $\left(v e h_{f}\right)$ is able to stop in the case of a stationary object in its path that only becomes visible once it has been passed by $v e h_{l}$ (i.e. $v e h_{l}$ physically blocked the sight line from $v e h_{f}$ to the object, until $v e h_{l}$ passes the object). This Scenario uses $-28.3 \mathrm{ft} / \mathrm{s}^{2}\left(8.6 \mathrm{~m} / \mathrm{s}^{2}\right)$ as the value of $a_{f}^{-}$.

Scenario \#1 is identical to the Baseline 'Weak' Scenario, with the exception that $a_{l}^{-}$is specified to be $-21.3 \mathrm{ft} / \mathrm{s}^{2}\left(6.5 \mathrm{~m} / \mathrm{s}^{2}\right)$, which is the maximum sustained braking rate reported by Fambro et al. (1997) for a passenger car on wet pavement. Comparing this scenario to the Baseline 'Weak' scenario tests the difference between capacity under conditions of dry and wet pavement.

In Scenario \#2, $a_{l}^{-}$is specified to be $-41.6 \mathrm{ft} / \mathrm{s}^{2}\left(12.7 \mathrm{~m} / \mathrm{s}^{2}\right)$, which is the maximum reported rate of deceleration for performance sports cars (specifically the Chevrolet Corvette and Porsche 911) (Motor Trend 2011). In this scenario, veh makes a moreconservative assumption that the maximum possible rate of deceleration of $v e h_{l}$ is the braking performance of a sports car, rather than a typical passenger car.

Scenario \#3 simulates a less-conservative assumption, in which $v e h_{f}$ assumes that it will brake at the same rate as $v e h_{l}$, regardless of how sharply $v e h_{l}$ brakes. Scenario \#3 provides no margin of error for $v e h_{f}$, as it implies that in the event of $v e h_{l}$ initiating emergency braking at any rate up to its maximum physically-achievable rate $v e h_{f}$ would also be able to reliably brake at the same rate.

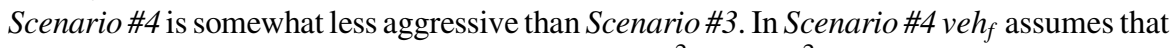
it will be able to, if required, brake at the rate of $28.3 \mathrm{ft} / \mathrm{s}^{2}\left(8.6 \mathrm{~m} / \mathrm{s}^{2}\right)$ that is typical of passenger cars (as in Scenario \#3), but the distinction is that $v e h_{f}$ makes the more-conservative assumption that $v e h_{l}$ could brake at the maximum rate of a representative sports car. 
The numerical deceleration values discussed up to this point have assumed that the braking rates sourced from the literature are point values, rather than drawn from a distribution. The reality, however, is that braking rates cannot be known in advance with full certainty. To accommodate this fact, we draw on empirical testing of antilock braking systems (ABS) performed by the US's National Highway Traffic Safety Administration, for which the results from individual emergency-braking test runs of a passenger sedan (Chevrolet Malibu) on four different days of dry conditions are published (NHTSA 2000 Tables E-4, F-4, G-4, and H-4). Using the standard deviation $\left(0.67 \mathrm{ft} / \mathrm{s}^{2}\left[0.20 \mathrm{~m} / \mathrm{s}^{2}\right]\right)$ of the results from 34 emergency stops $^{8}$ and an assumption that the results are distributed according to a standard normal distribution, ${ }^{9}$ we developed estimates of various percentile points of the distribution. The gap-selection strategy in Scenario \#5 is that veh $h_{f}$ assumes that $v e h_{l}$ will brake no more sharply than the 99.9th percentile of the distribution of typical passenger car braking on dry pavement $\left(-30.38 \mathrm{ft} / \mathrm{s}^{2}\left[9.26 \mathrm{~m} / \mathrm{s}^{2}\right]\right)$, and that it $\left(v e h_{f}\right)$ will brake no more weakly than the 0.1 th percentile of the same distribution $\left(-26.21 \mathrm{ft} / \mathrm{s}^{2}\right.$ $\left.\left[7.99 \mathrm{~m} / \mathrm{s}^{2}\right]\right)$. Assuming conservatively ${ }^{10}$ that the braking rates of $v e h_{l}$ and $v e h_{f}$ are uncorrelated, the joint probability of these two events $\left(a_{l}^{-} \geq 99 \% ; a_{f}^{-} \leq 1 \%\right)$ occurring is 1 in $1,000,000$ (i.e. $0.0001 \%$ ). In other words, $v e h_{f}$ is willing to subject its occupants to braking at the maximum physical limits of the vehicle, but assumes conservatively that there may be idiosyncrasies that make the achieved braking rate unknown a priori.

In Scenario \#6, veh $h_{f}$ assumes the standard $-28.3 \mathrm{ft} / \mathrm{s}^{2}\left(8.6 \mathrm{~m} / \mathrm{s}^{2}\right)$ value for $a_{l}^{-}$, but is unwilling to expose its ( $v e h_{f}$ 's) occupants to deceleration greater than the maximum rate of High-Speed Rail ( $-1.8 \mathrm{ft} / \mathrm{s}^{2}\left[0.5 \mathrm{~m} / \mathrm{s}^{2}\right]$, per CA-HSRA 2004). This Scenario therefore tests the consequence of AVs providing their occupants with a very high standard of ride quality, as characterized by maximum expected longitudinal deceleration; this Scenario is tested because some researchers (Smith 2012; Anderson et al. 2016; Gucwa 2014; Speiser et al. 2014) have suggested that automated vehicles may enable their occupants to devote their travel time to a similar degree of productivity/leisure as time spent on high-standard rail services.

Scenario \#7 specifies the standard $-28.3 \mathrm{ft} / \mathrm{s}^{2}\left(8.6 \mathrm{~m} / \mathrm{s}^{2}\right)$ value for $a_{l}^{-}$, and we then calculated the value of $a_{f}^{-}$required so that a free-flow speed of $75 \mathrm{miles} / \mathrm{h}(121 \mathrm{~km} / \mathrm{h})$ results in the maximum calculation of capacity (automated vehicles per lane per hour). This is because, as we report in "Results" section, we found that there is a strong negative relationship between free-flow speed and capacity.

Scenario \#8 is identical to the Baseline 'Weak' Scenario, except that it tests the sensitivity of the capacity calculation to an assumption of $t_{\text {lag,f }}=0$ (i.e. no time passes

\footnotetext{
8 The study's authors classified test drivers' braking efforts into classes 'A, 'B', 'C', and 'D', with class 'A' being the largest amount of force applied to the brake pedal. For the purposes of the present paper, we removed all stops in class ' $D$ ' prior to performing statistical analysis. These were stops in which the driver did not meet both of the following criteria: at least $50 \mathrm{lbf}$ (pound-force) of braking force within $0.2 \mathrm{~s}$ of brake application, and at least $100 \mathrm{lbf}$ within $0.3 \mathrm{~s}$. This eliminated 16 of the 50 stops, resulting in the dataset analyzed in the present study consisting of 34 stops. For the purposes of (NHTSA 2000), the authors of that study also 'accepted as valid' (Section 1-IV, paragraph a-4) stops in classes 'A', 'B', and 'C'.

9 We tested this assumption via the Shapiro-Wilk test; the null assumption that the data are normally distributed was supported (i.e. not rejected) at the $95 \%$ confidence level, though the test statistic $(p=0.07)$ was near to the critical value of $p=0.05$.

10 This is a conservative assumption because a degradation in rates of deceleration, as might perhaps be caused by an oily road surface, would be expected to affect both $v e h_{l}$ and $v e h_{f}$, which would result in positive correlation in their maximum physically-achievable braking rates.
} 
between $v e h_{l}$ and $v e h_{f}$ initiating emergency braking). ${ }^{11}$ In this scenario we assume that $v e h_{l}$ provides vehicle-to-vehicle communications to $v e h_{f}$ immediately upon initiating emergency braking, that this messaging is also received and processed instantly by $v e h_{f}$, and further that there is no delay at all while $v e h_{f}$ builds pressure in its braking system. This scenario, while implausible, was selected as the limiting case (i.e. none of these components of latency can be negative).

Finally, Scenario \#9 is identical to the Baseline 'Weak' Scenario, except that $x_{v e h}$ (the length of $v e h_{l}$ ) is increased by $25 \%$. In other words, this Scenario tests the sensitivity of the capacity calculations to the length of the vehicles in the traffic stream.

\section{Results}

In this section we present numerical results for mainline-segment freeway capacity (vehicles per lane per hour) in the presence of automated vehicles, on the basis of the criteria specified in "Methodology" section.

\section{Scenarios of ACDA-compliant automated car driving}

Figure $1^{12}$ shows calculated maximum throughput values for automated vehicles (Baseline 'Weak' and Strong' Scenarios and Scenarios \#1 through \#9), as well as comparisons to human driving behavior as characterized by the HCM-2010 and Wiedemann-1999 models. All curves initially increase from the origin, which reflects the fact that at very low speeds throughput is determined primarily by speed and vehicle length, rather than spacing between vehicles.

At highway speeds $(60+$ miles per hour $[97 \mathrm{~km} / \mathrm{h}]$ for the purposes of this discussion), we find that automated-car throughput decreases as speed increases (the only exceptions are Scenario \#3 and, to a lesser degree, Scenario \#7, which are based on implausibly aggressive assumed patterns of deceleration). This negative relationship is consistent with the HCM-2010 model of human-driving, but not the Wiedemann-1999 model, which shows no relationship between speed and capacity in the range 40-70 miles $/ \mathrm{h}^{13}$ (64-113 km/h). Compared against the HCM-2010 model of human drivers, for automated cars the rate of decrease (the slope of the curve) is smaller, demonstrating that the tradeoff between speed and throughput is less sharp for automated cars than HCM2010 predicts for human drivers (see also the discussion in "Fundamental diagram of ACDA-compliant automated car driving" section of Fig. 2).

\footnotetext{
11 Ahmed-Zaid et al. (2011) document the potential for latency values of under $0.1 \mathrm{~s}$ for transmissions and receipt of $\mathrm{V} 2 \mathrm{~V}$ messaging, including time delays to account for message authentication.

12 Tables A1, A2 and A3 contain the data for the curves plotted in Figs. 1, 2, and 4 respectively. These tables can be found in this article's online Supplementary Material, available at doi:10.1007/s11116-0179825-8.

13 At free-flow speeds above 70 miles/h $(113 \mathrm{~km} / \mathrm{h})$, simulations using the Wiedemann-1999 model become unstable, resulting in large variations in throughput when using identical inputs with the exception of different random 'seed' values. As comparing the HCM-2010 and Wiedemann-1999 models at very high speeds is not the primary objective of this study, we restrict our discussion of the Wiedemann-1999 results to free-flow speeds up to $70 \mathrm{miles} / \mathrm{h}(113 \mathrm{~km} / \mathrm{h})$. We note the discrepancy of flow properties at very high speeds between these two models of human driver behavior as an item in need of further enquiry, to determine which better characterizes human driving behavior in this specific context.
} 


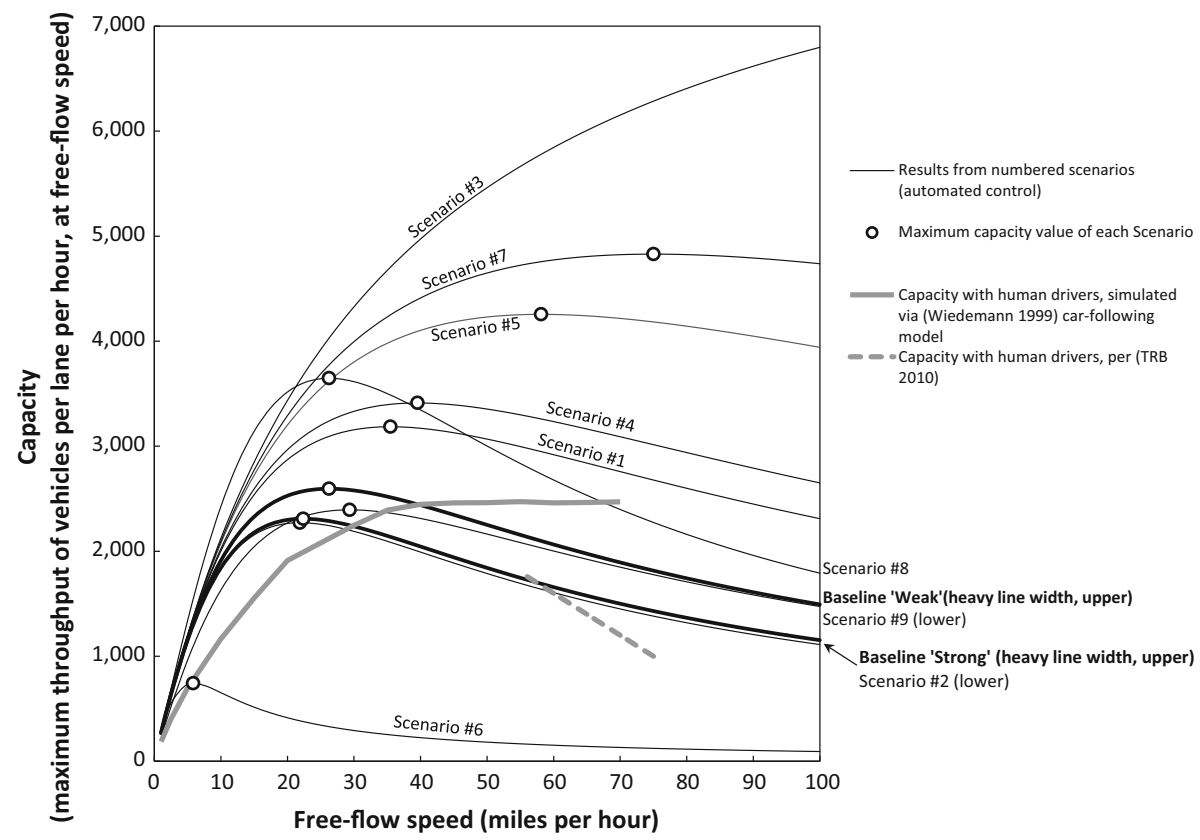

Fig. 1 Calculations of capacity for automated cars (Baseline 'Weak' and 'Strong' Scenarios and Scenarios \#1 through \#9), with comparisons to human-driving behavior (HCM-2010 and Wiedemann-1999)

At highway speeds, the Baseline 'Weak' Scenario shows a complex set of findings regarding throughput. The calculated maximum level of throughput (vehicles/lane/h) at a free-flow speed of $70 \mathrm{miles} / \mathrm{h}(113 \mathrm{~km} / \mathrm{h})$, for instance, of 1893 for automated cars is larger than the HCM-2010 calculation (1400 vehicles/lane/h) but smaller than the Wiedemann1999 simulated value of 2470 vehicles/lane/h. This is due to the divergence between the two human-driver models in their estimation of the relationship between throughput and speed at freeway speeds, with the Wiedemann-1999 model suggesting that free-flow speeds up to $70 \mathrm{miles} / \mathrm{h}(113 \mathrm{~km} / \mathrm{h})$ can be maintained at much higher volumes of traffic demand.

All plausible 'dry-pavement' Scenarios (i.e. excluding Scenario \#1, which is discussed immediately below, and Scenario \#8, which takes no account of latency $t_{\text {lag, } f}$ ) that result in greater throughput at $70 \mathrm{miles} / \mathrm{h}(113 \mathrm{~km} / \mathrm{h})$ than human drivers require that the occupants of automated vehicles be placed at risk of experiencing braking rates to avoid a rear-end crash that are near the passenger cars' maximum physically-attainable rates. In Scenario \#6, where automated car occupants are not at risk of deceleration exceeding that of High Speed Rail, capacity at $70 \mathrm{miles} / \mathrm{h}(113 \mathrm{~km} / \mathrm{h})$ is 132 vehicles per lane per hour. This demonstrates the fundamental challenge to reliably delivering high-standard ride quality in road vehicles, even under automated control.

On wet pavement (Scenario \#1), capacity is substantially higher (at all travel speeds) than on dry pavement if the ACDA criterion is interpreted to mean that an automated car must be able to stop to avoid striking the vehicle in front. This is consistent with findings in the context of ACDA-compliant operations of automated cars at signalized intersections (Le Vine et al. 2016). This finding arises because on wet pavement $v e h_{f}$ can have confidence that $v e h_{l}$ will not be able to brake as harshly as it $\left(v e h_{l}\right)$ could on dry pavement. We note that assumptions underpinning this scenario are in contrast to an interpretation of 


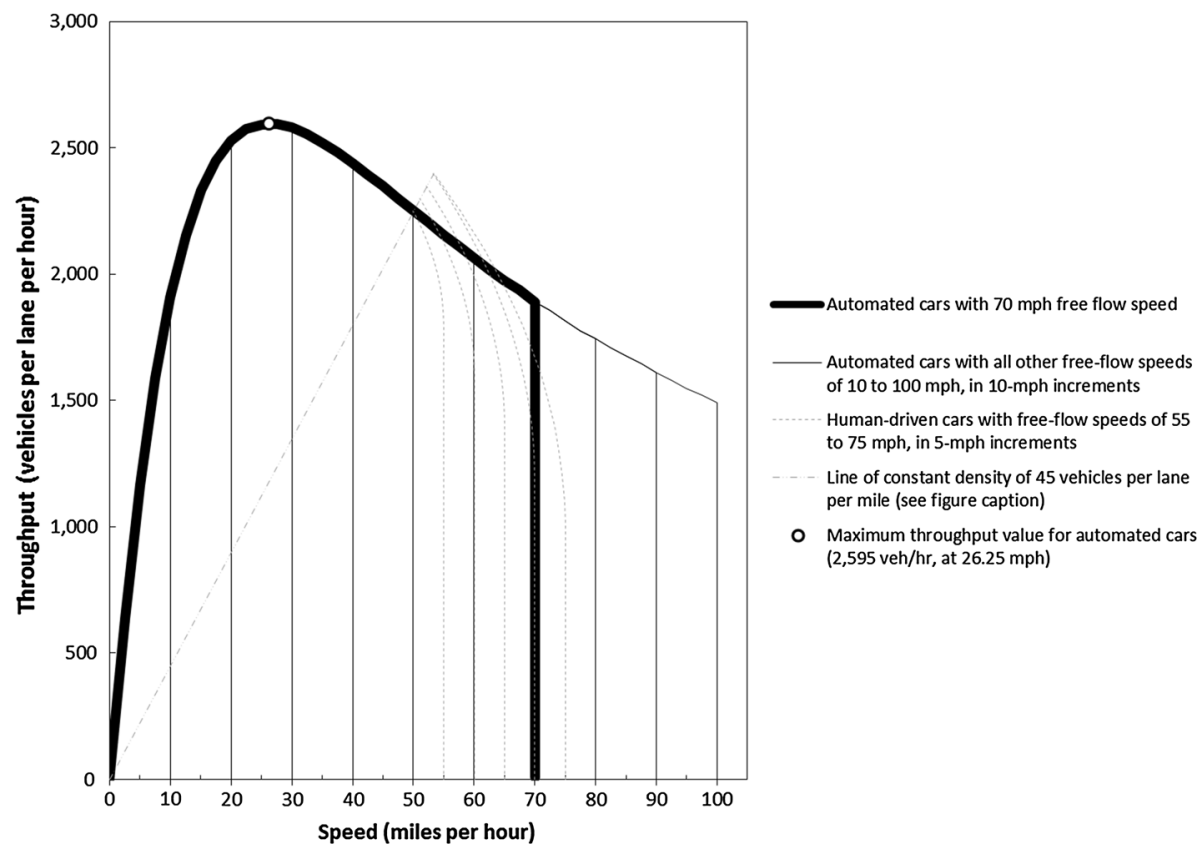

Fig. 2 Speed versus throughput for automated cars (solid curves) under the Baseline 'Weak' Scenario and human-driven cars (dashed curves) per the HCM-2010 model (dashed lines; reproduced from TRB (2010), Exhibit 11-2 and 11-3). HCM-2010 specifies 45 passenger cars per lane per hour as the density at which a standard freeway segment is operating at its maximum capacity at all speeds

ACDA to mean that a vehicle must be able to stop if a stationary previously-obscured object becomes visible, which is the subject of the Baseline 'Strong' Scenario; under this criterion capacity would be lower on wet pavement.

Comparing Scenario \#2 to the Baseline 'Weak' Scenario, it can be seen that there would be a substantial lessening of capacity if $v e h_{f}$ assumes that $v e h_{l}$ could brake at the rate of a performance sports car rather than a typical sedan-type automobile.

Scenario \#5 is of particular interest, as it introduces uncertainty in physically-attainable rates of deceleration into the analysis. In this Scenario $v e h_{f}$ is willing to accept a specific 1 in 1,000,000 risk if $v e h_{f}$ initiates emergency braking (i.e. that $a_{l}^{-}$will not exceed the 99.9th percentile of the dry-pavement braking distribution, and that $a_{f}^{-}$will exceed the 0.1 th percentile). The calculated value of automated-car capacity at 70 miles per hour $(113 \mathrm{~km} /$ h) is 4217 vehicles per hour per lane-more than four times the capacity at $70 \mathrm{mph}$ $(113 \mathrm{~km} / \mathrm{h})$ of human drivers, and a $76 \%$ gain relative to the 2400 vehicles/lane/h attainable by human drivers at any speed (this maximum occurs at $53 \mathrm{mph}(85 \mathrm{~km} / \mathrm{h})$ per the HCM-2010 model, see "Fundamental diagram of ACDA-compliant automated car driving" section below). We therefore conclude that the possibility of large gains in capacity exists even in the absence of cooperation between automated cars (i.e. without trusted, actionable V2V messaging), though this requires that the occupants of automated cars be at risk of sharp deceleration that is near to the physical limits of their vehicles.

Comparing Scenario \#8 to the Baseline 'Weak' Scenario shows the impact of the unattainable situation of zero latency $\left(t_{\text {lag. }}=0\right)$; maximum throughput at $70 \mathrm{miles} / \mathrm{h}$ 
$(113 \mathrm{~km} / \mathrm{h})$ is increased by $27 \%$. Scenario \#9 shows that a large change $(+25 \%)$ in vehicle length has a relatively marginal impact on automated car capacity at highway speeds (1849 vehicles per lane per hour, vs. 1893 for the Baseline Scenario).

The Baseline 'Strong' Scenario shows (relative to the Baseline 'Weak' Scenario), the effect of the 'strong' interpretation of ACDA. As would be expected, this strict interpretation results in a lower calculated value of maximum throughput than the Baseline Scenario (which is based on the 'weak' ACDA interpretation), at all travel speeds (e.g. 1501 vs. 1893 vehicles per lane per hour at $70 \mathrm{miles} / \mathrm{h}[113 \mathrm{~km} / \mathrm{h}]$, a decrease of $21 \%$ ).

\section{Fundamental Diagram of ACDA-compliant automated car driving}

The Fundamental Diagram is a standard method of displaying traffic flow properties, by showing any two of three quantities (speed, traffic density, and throughput ${ }^{14}$ ) plotted against one another (TRB 2010). Figure 2 shows the plot of speed versus throughput, using the parameters of the Baseline 'Weak' Scenario. Solid curves represent automated cars operating under constraints of various free-flow speeds (between 10 and 100 miles/h [16 and $161 \mathrm{~km} / \mathrm{h}$ ], in increments of 10), and dashed curves (derived from HCM-2010) show the analogous relationships for flow of human-driven cars on freeways with design speeds between 55 and 75 miles/h (89 and $121 \mathrm{~km} / \mathrm{h}$ ), in increments of $5 \mathrm{miles} / \mathrm{h}$ (HCM-2010 displays only the curves shown here; no relationships are presented for freeways with freeflow speeds below 55 miles $/ \mathrm{h}[89 \mathrm{~km} / \mathrm{h}]$ or higher than $75 \mathrm{miles} / \mathrm{h}[121 \mathrm{~km} / \mathrm{h}]){ }^{15}$

In Fig. 2, the vertical portion of each curve of free-flow-speed (for both automated and human-driven cars) can be interpreted to mean that as traffic flow increases from zero, traffic will continue to flow at its free-flow speed until some critical level of density, beyond which a drop-off in speed occurs. Each automated-car curve (solid lines) is separate from other curves for its vertical portion (which represents the relevant flor at the free-flow speed of each curve), however the portions of the curves representing congested flow (the nonlinear sections) overlap one another as free-flow speed is found not to be relevant in this region of flow. Four phenomena are noteworthy when comparing the automated-car curves to the human-driver curves.

First, the transition from free-flow speed occurs at a lower level of throughput for human drivers; this is shown by the 'human-drivers' curves beginning to turn towards the left (from vertical, moving upwards from the x-axis) at lower throughput levels than automated cars.

Second, the transition from free-flow to constrained-flow is less abrupt for human drivers. This is reflected by the human-driver curves initially turning smoothly towards the left from their free-flow speeds, whereas there is a distinct 'kink' (formally, a discontinuity in the derivative) on each of the curves for automated cars. The relationship between Figs. 1 and 2 is that (for the Baseline 'Weak' Scenario) the throughput values in Fig. 1 correspond to the throughput values of these 'kinks' in the Fig. 2 free-flow-speed curves.

\footnotetext{
14 If any two of these quantities are known, the third is also uniquely identified by the relationship that throughput equals the product of density and speed.

15 Reported freeway capacity values have increased over time in the various editions of the Highway Capacity Manual that have been published since 1950. For instance, Laufer (2007) notes that maximum achievable throughput (irrespective of speed) is reported as 2000, 2200 and 2400 vehicles/lane/h in the 1985, 1994 and 2000 editions of the HCM, respectively. Laufer attributes these changes to improved traffic engineering, vehicle performance capabilities, and also possibly due to "changes in societal driving patterns" (p. 3). Human driving behavior may therefore represent something of a moving target, which complicates using it as a benchmark to compare with automated control.
} 
This is also related to the relative steepness of the HCM-2010 curve in Fig. 1; while the HCM-2010 model suggests that there is a stronger negative relationship between free-flow speed and capacity for human drivers than for automated cars, the drop-off of the HCM2010 model from free-flow speed into congested speeds seen in Fig. 2 initially has a very gentle slope.

The third notable phenomenon that can be seen in Fig. 2 is that the maximum throughput value for automated cars (across all travel speeds; not limited to free-flow speed) is higher than for human drivers, even under the relatively conservative assumptions of the Baseline 'Weak' Scenario. For human drivers and automated cars, maximum throughput is 2400 and 2595 vehicles/lane/h, respectively; this represents a gain of $8 \%$.

Fourth, this maximum-achievable throughput of automated cars occurs at a lower speed (26 miles/h) than for human cars (53 miles/h $[85 \mathrm{~km} / \mathrm{h}])$. There is also a level of throughput (between approximately 2000-2250 and 2400 vehicles/lane/h, with the former of these values varying with human driver's free-flow speed) for which speed is calculated to be higher for human drivers than automated cars. This is represented visually by the region where the human-driver curves extend further to the right on Fig. 2 than the automated-car curves. It is noteworthy that the finding of maximum throughput at lower speed is in contrast to results reported by Barth (1997); using the model developed by Barth it was found that maximum throughput for platooning automated cars occurred at higher speeds than for human-driven cars.

Stated succinctly, our results suggest that automated cars (under the Baseline 'Weak' Scenario) would be able to sustain higher flow rates at their free-flow speed than human drivers can achieve, but that the initial rate of degradation (the decrease in speed below free-flow speed caused by an incremental increase in traffic volume past this critical flow level) is larger for automated cars. Automated cars also have both a higher level of throughput at their free-flow speed than human drivers, and a higher level of maximumachievable throughput (irrespective of speed).

\section{Capacity calculations under uncertainty, with various thresholds of crash risk}

Scenario \#5 introduced uncertainty regarding achieved braking rates into the analysis, in recognition that actual deceleration rates for any given emergency braking event represent a draw from a distribution rather than a point value that is known a priori with certainty. Scenario \#5 examined the effects of $v e h_{l}$ planning for the possibility that it might be able to brake relatively weakly (at the 0.01 th percentile of the distribution) while $v e h_{f}$ is able to brake relatively sharply (at the 99.9th percentile). In Table 4, we further investigate the effects of uncertainty in braking rates on capacity. This analysis takes account of both dimensions of uncertainty (in the value of both $a_{l}^{-}$and $a_{f}^{-}$) by drawing independently from two identical normal distributions with mean and standard deviation of 28.3 and $0.67 \mathrm{ft} / \mathrm{s}^{2}$ $\left(8.6\right.$ and $\left.0.20 \mathrm{~m} / \mathrm{s}^{2}\right)$, respectively (i.e. $a_{l}^{-}, a_{f}^{-} \sim N\left(-28.3 \mathrm{ft} / \mathrm{s}^{2}, 0.67 \mathrm{ft} / \mathrm{s}^{2}\right)$ ). In Table 4 we examine both the 'weak' and 'strong' interpretations of ACDA, in which $v e h_{f}$ seeks to avoid striking $v e h_{l}$ if $v e h_{l}$ begins emergency braking (the 'weak' interpretation), or conversely $v e h_{f}$ seeks to avoid striking a stationary object that becomes visible to $v e h_{f}$ only after $v e h_{l}$ passes the object (the 'strong' interpretation).

For the analysis of the 'weak' interpretation, a total of 10 million independent realizations were taken from each of the two normal distributions, and for each pair of deceleration values $\left(a_{l}^{-}\right.$and $\left.a_{f}^{-}\right)$the minimum headway and concomitant capacity values were obtained. For the analysis of the 'strong' interpretation, only the 10 million 
Table 4 Simulated maximum throughput values based on minimum calculated time gap (rear of $v e h_{l}$ to front of $v e h_{f}$ ) if $v e h_{l}$ and $v e h_{f}$ both attempt to brake at their physical maximum rate, using 10,000,000 random draws from independent normal distributions, on dry pavement with $v=70 \mathrm{miles} / \mathrm{h}(113 \mathrm{~km} / \mathrm{h})$ and $t_{\text {lag }}=0.4 \mathrm{~s}$

\begin{tabular}{|c|c|c|c|c|}
\hline \multirow[b]{2}{*}{$\begin{array}{l}\text { Probability } \\
\text { of crash }(\%)\end{array}$} & \multicolumn{2}{|c|}{$\begin{array}{l}\text { B C } \\
\text { Criterion is for } v e h_{f} \text { to avoid striking } v e h_{l} \text { if } \\
v e h_{l} \text { unexpectedly initiates emergency } \\
\text { braking }\end{array}$} & \multicolumn{2}{|c|}{$\begin{array}{l}\text { D E } \\
\text { Criterion is for } v e h_{f} \text { to avoid striking a } \\
\text { stationary object that becomes visible to } v e h_{l} \\
\text { only after } v e h_{l} \text { passes the object }\end{array}$} \\
\hline & $\begin{array}{l}\text { Minimum gap (s), } \\
\text { conditional on } \\
\text { veh } \text { accepting the }_{\text {crash risk in }} \\
\text { Column 'A' }\end{array}$ & $\begin{array}{l}\text { Maximum throughput } \\
\text { (veh/lane/h at } v=70 \\
\text { miles } / \mathrm{h}[113 \mathrm{~km} / \mathrm{h}]) \text {, } \\
\text { based on minimum } \\
\text { headway shown in } \\
\text { Column 'B' }\end{array}$ & $\begin{array}{l}\text { Minimum gap (s), } \\
\text { conditional on } \\
v^{e} h_{f} \text { accepting the } \\
\text { crash risk in } \\
\text { Column 'A' }\end{array}$ & $\begin{array}{l}\text { Maximum throughput } \\
(\mathrm{veh} / \mathrm{lane} / \mathrm{h} \text { at } v=70 \\
\text { miles/h }[113 \mathrm{~km} / \mathrm{h}]) \text {, } \\
\text { based on minimum } \\
\text { headway shown in } \\
\text { Column 'D' }\end{array}$ \\
\hline 0.0001 & 0.69 & 4108 & 2.44 & 1367 \\
\hline 0.001 & 0.66 & 4247 & 2.41 & 1383 \\
\hline 0.01 & 0.62 & 4426 & 2.38 & 1399 \\
\hline 0.1 & 0.58 & 4653 & 2.35 & 1416 \\
\hline 1 & 0.54 & 4953 & 2.31 & 1437 \\
\hline 2.5 & 0.51 & 5111 & 2.30 & 1447 \\
\hline 5 & 0.50 & 5255 & 2.28 & 1456 \\
\hline 10 & 0.47 & 5431 & 2.27 & 1466 \\
\hline 25 & 0.44 & 5751 & 2.24 & 1482 \\
\hline 50 & 0.40 & 6153 & 2.21 & 1501 \\
\hline 75 & 0.35 & 6616 & 2.18 & 1519 \\
\hline 90 & 0.32 & 7089 & 2.16 & 1535 \\
\hline 95 & 0.30 & 7423 & 2.14 & 1544 \\
\hline 97.5 & 0.28 & 7730 & 2.13 & 1553 \\
\hline 99 & 0.25 & 8123 & 2.11 & 1562 \\
\hline 99.9 & 0.21 & 9094 & 2.09 & 1582 \\
\hline 99.99 & 0.17 & 10,099 & 2.06 & 1598 \\
\hline 99.999 & 0.13 & 11,181 & 2.04 & 1613 \\
\hline 99.9999 & 0.10 & 12,283 & 2.02 & 1626 \\
\hline
\end{tabular}

realizations of $a_{f}^{-}$were used, as $a_{l}^{-}$is specified to be infinitely large. We note that this analysis accounts for only one specific source of uncertainty, of a type that can be readily characterized. Other plausible but less readily characterizable sources of variation in braking system performance which would tend to 'widen' the empirical distribution of braking rates include, inter alia, vehicle make/model/age, brake temperatures, tire condition, and idiosyncratic road surface imperfections.

The results of this analysis are shown in Table 4. The first row demonstrates that if the designer of an automated car's control algorithm selects the 'weak' interpretation of ACDA and wishes to accept no more than a one-in-a-million risk of a crash if the forward vehicle initiates emergency braking, the designer must specify a gap of no less than $0.69 \mathrm{~s}$ (on dry pavement, for traffic cruising at $70 \mathrm{miles} / \mathrm{h}[113 \mathrm{~km} / \mathrm{h}]$ ), which implies a maximum throughput at this speed of 4108 vehicles/lane/h. If the designer selects the 'strong' interpretation and the same crash risk, capacity is approximately 67\% lower (1367 vehicles/lane/h). 
Row \#3 of Table 4 demonstrates that if the designer selects a somewhat less-conservative criterion (a one-in-ten-thousand risk of a rear-end crash, in the event of $a_{f}^{-}$initiating emergency braking), capacity at $70 \mathrm{miles} / \mathrm{h}(113 \mathrm{~km} / \mathrm{h}$ ) would increase by $8 \%$ (4426 vs. 4108 ) and $2 \%$ relative to the 'one-in-a-million' risk threshold for the 'weak' and 'strong' interpretations, respectively.

The tenth row, to take a further example, shows that in order to achieve a capacity value at $70 \mathrm{miles} / \mathrm{h}(113 \mathrm{~km} / \mathrm{h})$ of 6153 vehicles/lane/h, automated cars would need to be programmed according to the 'weak' interpretation and also accept a 50\% risk of striking the vehicle ahead in the event that the leading vehicle suddenly begins emergency braking. At the upper end of the distribution, the final row of Table 4 shows that capacity values in excess of 12,000 vehicles/lane/h can in theory be achieved under the 'weak' interpretation, but this requires that each automated car runs a 999,999 out of 1,000,000 risk (i.e. a nearcertainty) that it will strike the vehicle ahead if the leading vehicle initiates emergency braking. In general, throughput values for the 'strong' criterion are both much lower and much less variable across different possibility-of-crash values; the latter effect is due to there being only one degree of freedom $\left(a_{f}^{-}\right)$, as $a_{l}^{-}$does not enter the analysis.

\section{Comparisons to human driving}

Drawing on empirical datasets, we now address two issues relating exclusively to human drivers, and a third relating to the interaction between human-driven and automated-control vehicles in mixed traffic:

1. What is the frequency at which human drivers perform high rates of deceleration? ("Human drivers' rates of deceleration" section)

2. On congested freeways, do human drivers comply with the ACDA Rule? ("Human drivers' degree of compliance with the ACDA Rule" section, and

3. Is it likely that human drivers would 'cut-in' into the ACDA-compliant gap ahead of an automated car? ("Potential for human-driver cut-ins" section)

\section{Human drivers' rates of deceleration}

We address the first of these questions by drawing on the Naturalistic Driving Study (NDS) (TRB 2013), in which 3645 participants at six regions across the U.S. had their private vehicles instrumented for extended periods during the 2010-2013 period $(n=5.4$ million journeys). Figure 3, prepared from tabulated data published by the NDS study team, shows the distribution of journeys by the maximum rate of deceleration experienced during each journey. The median journey experiences a maximum rate of deceleration between 9.7 and $12.9 \mathrm{ft} / \mathrm{s}^{2}\left(3.0\right.$ and $\left.3.9 \mathrm{~m} / \mathrm{s}^{2}\right)$, though there is a long lower tail. Roughly one journey in a thousand (i.e. $0.1 \%$ ) experiences deceleration greater than $29.9 \mathrm{ft} / \mathrm{s}^{2}\left(9.1 \mathrm{~m} / \mathrm{s}^{2}\right)$. Given that a one in a thousand risk is likely to be far too frequent to be selected as a crash-risk criterion, the NDS data appear to support the Baseline 'Weak' Scenario specification of automated cars assuming that the vehicle immediately ahead could unexpectedly brake at or near the vehicle's physical limits. 


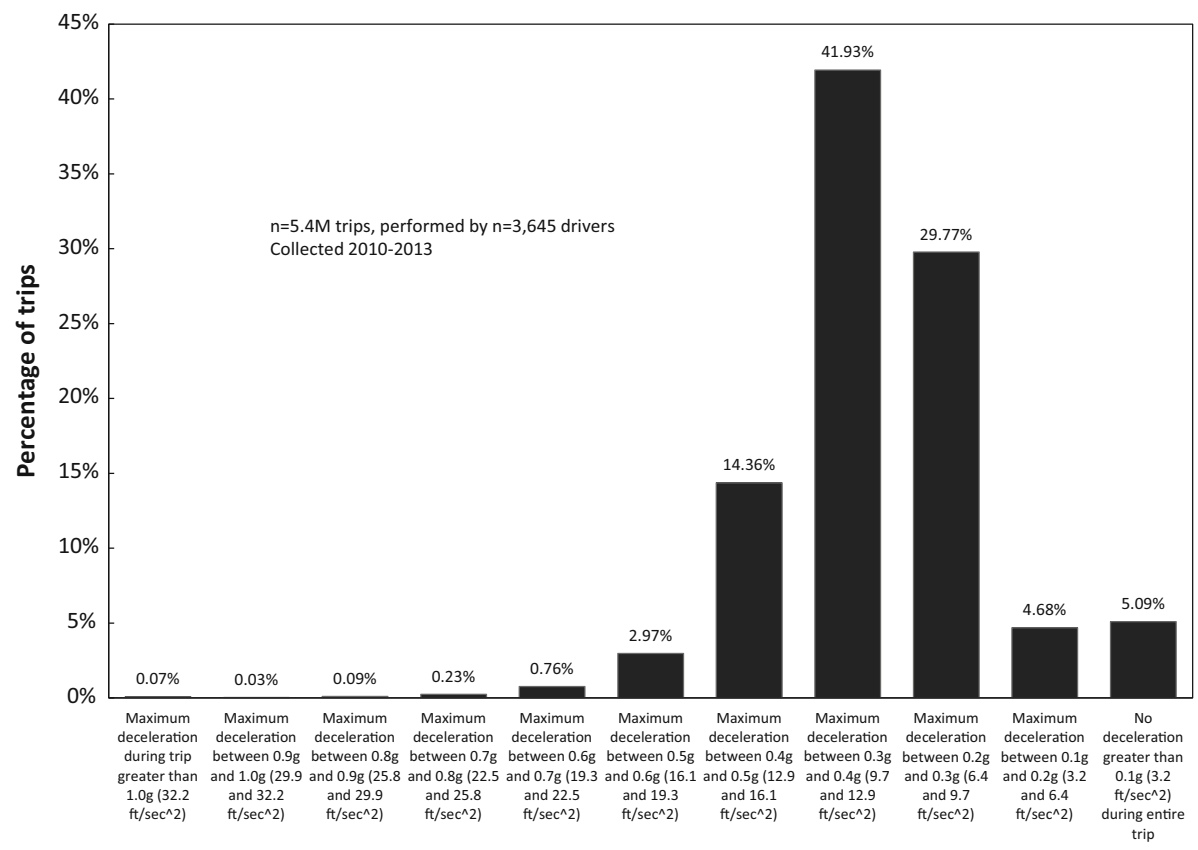

Fig. 3 Distribution of journeys observed in the SHRP2 dataset (TRB 2013) by maximum rate of deceleration during each journey

\section{Human drivers' degree of compliance with the ACDA Rule}

We addressed the second of these questions through analysis of disaggregate vehicletrajectory data from the Next Generation Simulation (NGSIM) study (USDOT 2016). The NGSIM data were collected via video observation of three sites in California. We employ vehicle-trajectory data from the US 101 freeway site, which was collected from 7:50 to 8:35 AM on 6/15/2005; during this period traffic flow transitioned from uncongested to congested conditions. Each vehicle's location and velocity are observed at $0.1 \mathrm{~s}$ intervals. After removing all heavy vehicles and motorcycles (which have distinctive deceleration profiles), and all instances when an automobile was following either a heavy vehicle or a motorcycle, we applied Eq. 2 to each automobile at each time-step, using various sets of parameter values as shown in Table 5. Table 5 shows that, even under implausibly aggressive assumptions about reaction time and rates of deceleration, human drivers on US Route 101 regularly violate the ACDA criterion. For instance, Scenario NGSIM-9 shows that even if a human driver is prepared to brake at its vehicle's maximum physicallyattainable rate (with $-28.3 \mathrm{ft} / \mathrm{s}^{2}\left[8.6 \mathrm{~m} / \mathrm{s}^{2}\right]$ specified as this value) and the driver assumes zero reaction time, human drivers are in violation of the ACDA rule $0.2 \%$ of the time under these assumptions. Under more-plausible assumptions (see, e.g., Scenarios NGSIM-11 through NGSIM-14, shown in Table 5), human drivers can be inferred to have violated ACDA between 1.5 and $49 \%$ of the time. It appears that while the ACDA criterion is the standard to which human drivers are held for legal purposes, in practice human drivers regularly violate it on congested freeways. 
Table 5 Percentage of time that human drivers on a congested freeway are in violation of the ACDA Rule, using the U.S. 101 NGSIM dataset

\begin{tabular}{lllll}
\hline Scenario & $a_{l}^{-}\left(\mathrm{ft} / \mathrm{s}^{2}\right)$ & $a_{f}^{-}\left(\mathrm{ft} / \mathrm{s}^{2}\right)$ & $t_{\text {lag.f }}(\mathrm{s})$ & $\begin{array}{l}\text { Percentage of time that human drivers are in } \\
\text { violation of the ACDA rule }(\%)\end{array}$ \\
\hline NGSIM-1 & $28.3\left(8.6 \mathrm{~m} / \mathrm{s}^{2}\right)$ & $16.4\left(5.0 \mathrm{~m} / \mathrm{s}^{2}\right)$ & 0 & 1.8 \\
NGSIM-2 & 28.3 & 16.4 & 0.1 & 2.9 \\
NGSIM-3 & 28.3 & 16.4 & 0.5 & 12.5 \\
NGSIM-4 & 28.3 & 16.4 & 0.7 & 20.3 \\
NGSIM-5 & 28.3 & 16.4 & 1 & 33.7 \\
NGSIM-6 & 28.3 & 16.4 & 1.75 & 63.5 \\
NGSIM-7 & 28.3 & 16.4 & 2.5 & 80.3 \\
NGSIM-8 & 28.3 & 16.4 & 3.5 & 90.0 \\
NGSIM-9 & 28.3 & 28.3 & 0 & 0.2 \\
NGSIM-10 & 28.3 & 28.3 & 0.1 & 0.3 \\
NGSIM-11 & 28.3 & 28.3 & 0.5 & 1.5 \\
NGSIM-12 & 28.3 & 28.3 & 0.7 & 4.4 \\
NGSIM-13 & 28.3 & 28.3 & 1 & 13.9 \\
NGSIM-14 & 28.3 & 28.3 & 1.75 & 49.3 \\
NGSIM-15 & 28.3 & 28.3 & 2.5 & 74.0 \\
NGSIM-16 & 28.3 & 28.3 & 3.5 & 88.0 \\
\hline Valnes & & & 0.5 & 0.5
\end{tabular}

Values of $t_{\text {lag,f }}$ are sourced as follows: 0 is the lower bound; 0.1 is a near-zero value; 0.5 and $0.7 \mathrm{~s}$ are the lowest value of human-driver latency time before braking in response to anticipated and unexpected objects (respectively) consistently observed per table C-3; $1.0 \mathrm{~s}$ is the approximate mean latency time, per table C-5; $1.75 \mathrm{~s}$ is the 99th percentile latency time for unexpected objects per table C-6; 2.5 and $3.5 \mathrm{~s}$ are the 95th and 99th percentile latency time for unexpected objects when observation by the researcher is covert, per Table C-6; all references in this note refer to Fambro et al. (1997)

\section{Potential for human-driver cut-ins}

The third question arises as to whether the headways required for automated cars to be ACDA compliant would result in human drivers unilaterally performing 'cut-in' maneuvers in heavy traffic, by changing lanes into the assured clear distance of an AV [cf. Milanes and Shladover (2016) in the context of for platoons of CACC-equipped cars]. In order to address this question, we compared the spacing that ACDA-compliant AVs would leave ahead of themselves (see Fig. 4) with empirical evidence on the size of gaps accepted by human drivers in congested traffic, using the NGSIM U.S. 101 dataset (see Table 6). Table 6 shows average spacing (distance between the rear of $v e h_{l}$ and the front of $v e h_{f}$ ), at the point in time when a third vehicle changes lanes to place itself between $v e h_{l}$ and $v e h_{f}$. The average values range from 109 to 151 feet $(33-46 \mathrm{~m})$, with average speeds in the range of $18-26 \mathrm{miles} / \mathrm{h}(29-42 \mathrm{~km} / \mathrm{h})$. At this speed range, the spacing values of AVs are less than 50 feet $(15 \mathrm{~m})$ for all Scenarios, as seen in Table A3 of this paper's Online Supplementary Material (except the implausible Scenario \#7 in which the automated vehicle's occupants have a ride quality similar to High Speed Rail). Therefore, on the basis of automated cars' ACDA-compliant spacing being no more than approximately half of the average spacing at which human drivers perform lane changes, we conclude that ACDA-compliant AVs appear to not be vulnerable to the average 'cut-in' maneuver by a human driver at speeds up to $25 \mathrm{miles} / \mathrm{h}(40 \mathrm{~km} / \mathrm{h})$. This accounts for the average spacing of humans' 'cut-in' 


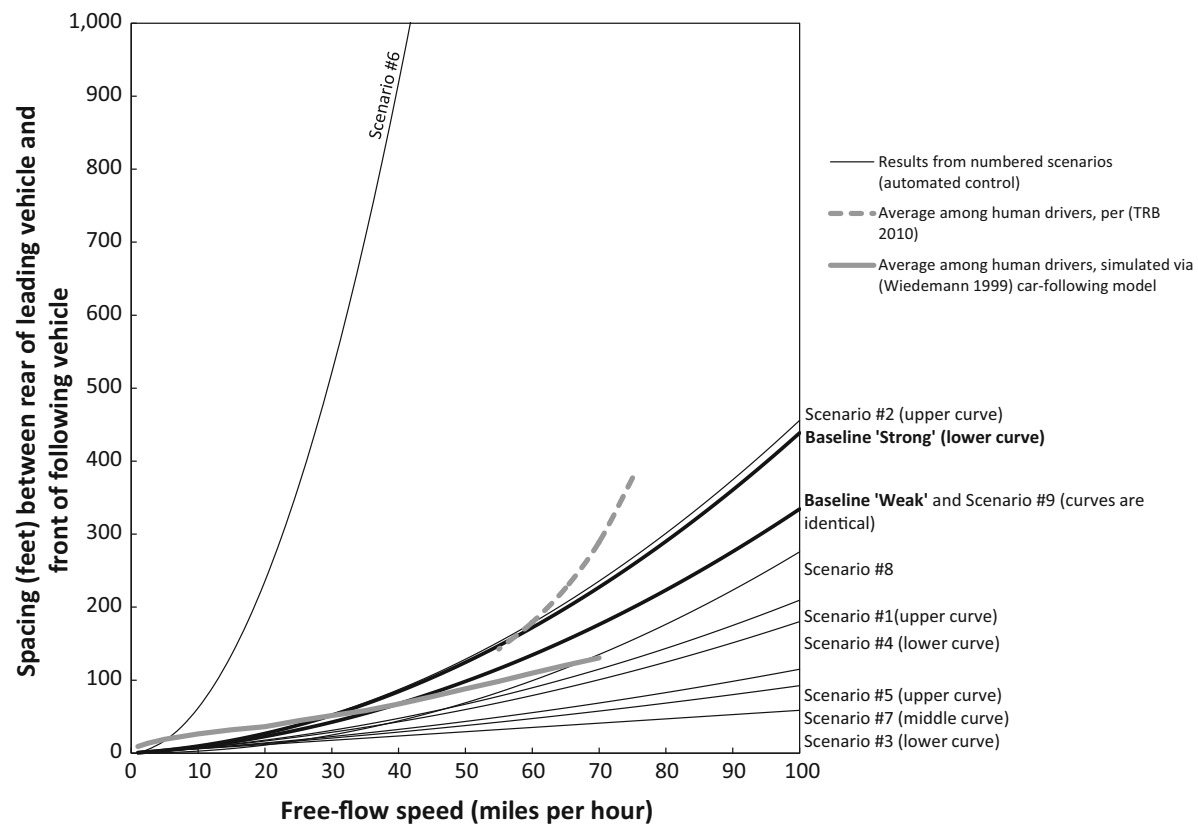

Fig. 4 Calculations of spacing (rear of $v e h_{l}$ to front of $v e h_{f}$ ) for automated vehicles (Baseline 'Weak' and 'Strong Scenarios and Scenarios \#1 through \#9), with comparisons to human-driving behavior (HCM-2010 and Wiedemann-1999)

Table 6 Size (feet) of gaps selected by human drivers when changing lanes on a congested freeway, from the U.S. 101 NGSIM dataset (Cambridge Systematics 2005)

\begin{tabular}{|c|c|c|c|c|}
\hline $\begin{array}{l}\text { Time } \\
\text { period }\end{array}$ & $\begin{array}{l}\text { Average } \\
\text { speed of } \\
\text { traffic (space } \\
\text { mean speed, } \\
\text { miles/h) }\end{array}$ & $\begin{array}{l}\text { Average forward spacing } \\
\text { (feet) of vehicles that } \\
\text { changed lanes, } \\
\text { immediately following } \\
\text { the lane change }\end{array}$ & $\begin{array}{l}\text { Average rear spacing } \\
\text { (feet) of vehicles that } \\
\text { changed lanes, } \\
\text { immediately following } \\
\text { the lane change }\end{array}$ & $\begin{array}{l}\text { Average overall spacing } \\
\text { (feet) immediately prior to } \\
\text { lane change, including an } \\
\text { assumed vehicle length of } \\
19 \text { feet }\end{array}$ \\
\hline $\begin{array}{c}7: 50 \text { to } \\
8: 05 \\
\text { AM }\end{array}$ & 25.7 & 63.4 & 69.0 & 151.4 \\
\hline $\begin{array}{c}8: 05 \text { to } \\
8: 20\end{array}$ & 21.6 & 46.6 & 56.6 & 122.2 \\
\hline $\begin{array}{c}8: 20 \text { to } \\
8: 35\end{array}$ & 18.0 & 41.1 & 48.6 & 108.7 \\
\hline
\end{tabular}

maneuvers; further research is needed to evaluate the distribution of these spacing values in order to state with greater credibility how vulnerable ACDA-compliant vehicles would be to relatively aggressive 'cut-in' maneuvers by human drivers.

\section{Conclusions}

This paper presents a novel exposition of the Assured Clear Distance Ahead criterion associated with negligence in rear-end car crashes, followed by a numerical analysis of the impacts of ACDA-compliant AVs on freeway mainline capacity. Our focus is primarily on 
unconnected AVs, i.e. in which each vehicle maintains the primary responsibility for its actions. A set of scenarios was evaluated and compared to human drivers, in the interest of exposing the general properties of flow of ACDA-compliant AVs. We present a novel investigation of the consequences of risk-averse car-following behavior which explicitly accounts for uncertainty in braking system performance.

This research highlights a fundamental tension, namely that human drivers are in principle held to the ACDA standard but routinely violate it in practice, and this 'negligent' driving tends to increase traffic-moving capacity (i.e. to lower congestion). We demonstrate that, even if ACDA is deemed to be applicable for AVs as it is for human drivers and $\mathrm{V} 2 \mathrm{~V}$ signaling is deemed unreliable for the purposes of selecting following distances, large gains in freeway capacity are nevertheless possible. A requirement, however, is that the occupants of automated cars must be placed at risk of deceleration at or near their vehicle's maximum physically attainable rate, which places limits on the cabin configuration of automated cars and the types of activities that their occupants can perform while traveling. While V2 V signaling could in principle allow even greater capacity, this would require a level of trust in others that is not reflected in current rules of the road. ${ }^{16}$

An additional tension is that cars following one another closely on a freeway provides benefits mainly to upstream vehicles, in the form of decreased congestion. The occupants of the vehicle performing the close following, however, receive little in the form of direct benefit (time savings) and bear a higher risk of being held liable for striking the vehicle ahead in the traffic stream. Circumstances in which there is a systematic mismatch between the distribution of benefits and costs to public and private actors can result in suboptimal outcomes, however; this is a classic collective action problem (Ostrom 2015).

We now conclude this paper with a brief discussion of research needs for the next phase of the research agenda.

First, this research highlights the need for a program of testing the emergency braking capabilities of AVs. There is also a need to confirm through field testing whether or not the kinematic parameters employed in this paper will continue to be valid. The empirical degree of error-correlation between the braking rates of a leading and a following vehicle is a further issue in need of further enquiry; this study's assumption of independence (see "Capacity calculations under uncertainty, with various thresholds of crash risk" section) is likely to be conservative. Given that the consequences of unconnected automation could include substantial gains or losses of capacity on the publicly-owned freeway network, there appears to be a case for public dissemination of the full technical results, which would of course need to be balanced against the commercial interests of AVs' manufacturers.

Second, further research is needed into the traffic flow properties of ACDA-compliant AVs in congested conditions. The analysis presented here does not account for possible 'shockwave' phenomena in traffic streams of automated vehicles, which is complex for two reasons. The 'shockwave' phenomenon in human-driven traffic streams is itself neither "well-understood" nor "accurately modeled in existing models" (Yeo and Skarbadonis 2009, both quotes from p. 99). Different manufacturers' AVs will also likely operate in

\footnotetext{
16 Naffky (2012, Sect. 648) reports that: "A motorist may assume that other travelers will obey the rules of the road and act on that assumption, at least in the absence of anything that in the exercise of reasonable care would put him on notice to the contrary. According to other authority, a driver may 'presume' that other travelers will obey the rules of the road [such as advance signaling of maneuvers], but cannot 'assume' that they will since no person has a right to anticipate due care of obedience to the law on the part of others...circumstances may arise where a temporary violation thereof [of motor vehicle law] is excusable or even imperative". See also footnote \#20.
} 
idiosyncratic ways, though for reasons of commercial sensitivity and the absence of large fleet sizes (100 s of vehicles) available for on-road testing, there is limited evidence today on which to base reliable conclusions. Therefore, researchers using simulation methods would need to make operational assumptions of parameters for which much less knowledge currently exists in the public domain, in comparison to the set of assumptions made in the kinematic model presented in this paper.

Third, the ACDA rule is not the only plausible standard for 'reasonable' operation of automated vehicles; research is needed into both the various interpretations of ACDA ('strong' vs. 'weak') and alternatives to ACDA. For instance, a government may reach a considered conclusion that the benefits from increased capacity (and avoided costs from postponing/canceling planned road-widening projects) of non-ACDA-compliant operation of automated vehicles outweigh the marginal costs of a heightened risk profile, and may therefore plausibly define manufacturers' duty of care to permit (or require) more aggressive driving behavior than ACDA permits. ${ }^{17}$ Glancy et al. (2016) note the possibility of 'safe harbor' legislation or regulation that could provide manufacturers a defense against liability on the basis of satisfying a safety standard set by policymakers. Even if such policies are enacted by neither legislation nor regulation, Anderson et al. (2016) note that it is likely that AV manufacturers will argue in court that the 'reasonableness' standard in allocating liability should consider AVs' societal cost-benefit analysis (which the authors expect to be demonstrably favorable), whereas plaintiffs in AV crashes may by contrast be incentivized to argue that 'reasonableness' is to be determined on the basis of a narrower cost-benefit analysis limited to the specific component of the AV-driving algorithm that governed the vehicle's behavior proximate to the crash. If, however, the ACDA criterion as it is applied to human drivers is treated as the relevant criterion for AVs' operation, guidance will be needed regarding whether AVs driving on limited-access freeways may/ should/must interpret the ACDA criterion 'weakly' or 'strongly'. Also, any departure from the ACDA criterion in the interest of maximizing capacity (or in locations where it cannot be guaranteed, such as on weaving segments of freeways) would require in-depth analysis to determine whether chain-reaction collisions can be avoided when an initial crash occurs in a traffic stream of vehicles that are not operating in ACDA compliance and, if not then how the costs of the crash are allocated. ${ }^{18}$ Shladover (1997) studied the problem of subACDA-compliant spacing, highlighting the fact that in AV platoons with very close headways any crashes would be relatively low-energy impacts (because there is little distance for differential rates of deceleration to lead to large speed differences), however in the process of longitudinally forming a platoon there is unavoidably a point at which ACDA compliance is impossible but the headway has not yet become small enough to ensure a low-energy crash.

\footnotetext{
17 Anderson et al. (2016, p. 142) report that "International air travel, nuclear power, and vaccines are all areas in which a promising technology received the subsidy of liability protection", but subsequently argue that "even if AV [automated vehicle] technology creates considerable positive externalities, it is not clear that altering the tort system is the best way to subsidize it".

18 Naffky (2012, pp. 129-131) reports that "Ordinarily, where a chain of events begins, due to the negligence of the owner or driver of an automobile, he may be liable for all mishaps that are properly the proximate result of his improper conduct... In cases involving successive car accidents, proximate cause is resolved as a matter of law based on the following considerations: (1) lapse of time; (2) whether the force initiated by the original wrongdoer continued in active operation up to the injury; (3) whether the act of the intervenor [an intervening cause is a new and independent force that breaks the causal connection between the original wrong and the injury] can be considered extraordinary; and (4) whether the intervening act was a normal response to the situation created by the wrongdoer.".
} 
Fourth, there is a need to quantitatively establish the safety/efficiency tradeoffs in the context of AVs' control. The fact that kinematic parameters cannot be known a priori with certainty means that there is no combination of car-following distance and speed that could completely eliminate the possibility of striking the leading vehicle. Therefore, research that rigorously exposes, in numerical terms, the specific safety/efficiency tradeoffs (extending from the initial analyses that we report in "Capacity calculations under uncertainty, with various thresholds of crash risk" section) would enable manufacturers to design algorithms for which it can be demonstrated that the anticipated benefits exceed the anticipated costs (cf. the discussion in LaValley [2013] of the precedent established in United States v Carroll Towing [1947] ${ }^{19}$ to determine whether a party has performed an adequate duty of care).

Fifth, the fact that maximum throughput for AVs is calculated to occur at much lower speed (26 miles/h [42 km/h]) than for human drivers is a novel speed/capacity tradeoff that requires further research. This tradeoff is an undesirable system-level property because it introduces a new type of tension between two of the principal objectives of the transportation network.

Sixth, there is a general need to establish the circumstances under which V2X messages can be regarded as trustworthy and complete, and hence actionable for safety-critical decision-making. For instance, it is unclear at present how liability would be allocated in case of the failure of a leading vehicle's $\mathrm{V} 2 \mathrm{~V}$ signaling to be received and processed by a following vehicle. ${ }^{20}$

Seventh, research is required to establish which person or entity is responsible in the event of non-ACDA-compliant driving by an AV, and how this may depend on circumstance. In circumstances where a human driver has made an informed selection of a speed and headway combination that is not ACDA-compliant and then instructed their vehicle to mimic this behavior in automated mode, it may be that the human driver bears some degree of responsibility in the event of a rear-end crash while in automated-driving mode. In this context, it is noteworthy that at least one designer of automated vehicle control algorithms (Urmson et al. 2015) has proposed a 'learning period' during which a human driver drives their automated car, while the vehicle 'learns' the human's driving style which it subsequently aims to mimic. In such a set of circumstances, the designer of the control algorithm might assert that the end user is at least partly liable in case of a rear-end crash while in automated mode, by claiming that the end user gave instructions to not follow the ACDA rule by not himself/herself having driven in an ACDA-compliant manner during the learning period. If, however, the owner/occupant of an automated car has never given instructions (or anything that can be construed as 'instructions') to an automated car regarding driving style, it may be more likely that liability for failing to comply with ACDA would rest with the manufacturer.

\footnotetext{
${ }^{19}$ In (United States v. Carroll Towing 1947), it was held that duty of care is a function of three variables: the probability $P$ of a harm occurring, the loss $L$ to the person who is owed the duty of care if the harm occurs, and the burden $B$ (or cost) of preventing the harm. The rule would accept that one's duty is to incur costs for which the cost is less than the expected loss: $B<P L$.

${ }^{20}$ Regarding the requirements for maintain a vehicle generally and "signaling devices" specifically, Naffky (2012, Sects. 621, 623, 668) reports: "The duty to exercise due care in the operation of a motor vehicle by use of signals and warnings ordinarily carries with it a duty to have the vehicle equipped with a horn, bell, or other signaling device...[However,] lack of warning equipment in working order will not constitute actionable negligence unless such lack proximately causes an injury...[Further,] regulations as to signals, whether statutory or otherwise, call for the minimum of care and not the maximum.".
} 
Eighth, this research is intended to provide support for transportation planners simulating the effects of AVs in regional travel-demand models. Therefore, there is a need to adapt the volume-flow relationships we report here (e.g. Fig. 2) into curves analogous to the volume-delay curves employed in travel demand models. This research would ideally involve algorithms that account for spillback during periods of oversaturated demand.

From the earliest days of vehicle automation, it has been recognized that "the most effective (and proactive) method to control costs related to liability is through careful product design and careful system operation" (Stevens 1997, p. 344). It is the authors' hope that this research will assist researchers, designers and policymakers in understanding the degree of care required in automated cars' operation, and the attendant consequences for traffic flow.

Acknowledgements The authors wish to thank the reviewers for useful feedback, and Steven Shladover for helpful discussions regarding the technical capabilities of automated vehicle sensing and control systems. Le Vine acknowledges financial support of the University Transportation Research Center, Region 2 (Grant \# 49198-13-28, titled: Drive Cycles of Automated Vehicles), and Liu acknowledges support from the Chinese National Science Foundation (Grant \# 71671147). The usual disclaimer applies: any errors in this paper are the authors' sole responsibility. On behalf of all authors, Le Vine states that there is no conflict of interest.

Open Access This article is distributed under the terms of the Creative Commons Attribution 4.0 International License (http://creativecommons.org/licenses/by/4.0/), which permits unrestricted use, distribution, and reproduction in any medium, provided you give appropriate credit to the original author(s) and the source, provide a link to the Creative Commons license, and indicate if changes were made.

\section{References}

Ahmed-Zaid, F., Bai, F., Bai, S., Basnayake, C., Bellur, B., Brovold, S., Brown, G., Caminiti, L., Cunningham, D., Elzein, H., Hong, K., Ivan, J., Jiang, D., Kenney, J., Krishnan, H., Lovell, J., Maile, M., Masselink, D., McGlohon, E., Mudalige, P., Popovic, Z., Rai, V., Stinnett, J., Tellis, L., Tirey, K., VanSickle, S.: Vehicle Safety Communications - Applications (VSC-A) Final Report: Appendix Volume 3 Security. Retrieved 7/15/2017 via: http://www.nhtsa.gov/DOT/NHTSA/NVS/Crash\% 20Avoidance/Technical\%20Publications/2011/811492D.pdf (2011)

American Association of State Highway and Transportation Officials (AASHTO): A Policy on Geometric Design of Highways and Streets, 6th edn. https://bookstore.transportation.org/collection_detail. aspx?ID=110 (2011)

Anderson, R., Doecke, S., Mackenzie, J., Ponte, G.: Potential benefits of autonomous emergency braking based on in-depth crash reconstruction and simulation. In: Proceedings of the 23rd International Conference on Enhanced Safety of Vehicles, US National Highway Traffic Safety Administration, Washington DC (2013)

Anderson, J., Kalra, N., Stanley, K.D., Sorenson, P., Samaras, C., Oluwatola, O.: Autonomous Vehicle Technology: A Guide for Policymakers. RAND Corporation, Santa Monica (2016)

Asare, S.K., McGurrin, M.: Assessing operational impacts of connected automation. In: 95th Annual Meeting of the Transportation Research Board, January 2016, Washington, DC (2016)

Barth, M.J.: The effects of AHS on the environment. In: Ioannou, P.A. (ed.) Automated Highway Systems. Springer, New York (1997)

Bergenhem, C., Coelingh, E., Johansson, R., Tehrani, A.: V2V communication quality: measurements in a cooperative automotive platooning application. SAE Int. J. Passeng. Cars Electron. Electr. Syst. 7(2), 462-470 (2014). doi:10.4271/2014-01-0302

Bierstedt, J., Gooze, A., Gray, C., Peterman, J., Raykin, L., Walters, J.: Effects of Next-Generation Vehicles on Travel Demand and Highway Capacity. Retrieved 7/15/2017 via: http://orfe.princeton.edu/ alaink/ Papers/FP_NextGenVehicleWhitePaper012414.pdf (2014)

Blum, G., Eclavea, R.P., Levin, J.K., Kane, R., Shampo, J., Surette, E., Harnad, G.K., Melley, A.E., Morris, M.B.: American Jurisprudence: Carriers, 2nd edn. http://legalsolutions.thomsonreuters.com/lawproducts/Legal-Encyclopedias/American-Jurisprudence-2d/p/100027544 (2016)

Bove v. Beckman: Civ. No. 27853. Second Dist., Div. Three. 16 Aug 1965 
Brackstone, M., Sultan, B., McDonald, M.: Motorway driving behaviour: studies on car following. Transp. Res. Part F Traffic Psychol. Behav. 5, 329-344 (2002)

Brackstone, M., McDonald, M.: Car-following: a historical review. Transp. Res. Part F Traffic Psychol. Behav. 2, 181-196 (1999)

Brackstone, M., McDonald, M.: Driver headway: how close is too close? Ergonomics 50(8), 1183-1195 (2007)

Buchwalter, J.D., Danne, W.H., Dvorske, J.J., Dietz, L.H., Eclaves, R.P., Esping, E.K., Larsen, S., Levin, J.K., Lindsley, W., Muskus, T., Sutette, E.C.: American Jurisprudence: Automobiles and Highway Traffic, 2nd edn. http://legalsolutions.thomsonreuters.com/law-products/Legal-Encyclopedias/ American-Jurisprudence-2d/p/100027544 (2016)

Burnham, G., Seo, J., Bekey, J.: Identification of human driver models in car following. IEEE Trans. Autom. Control 19(6), 911-915 (1974)

California High-Speed Rail Authority [CA-HSRA]: Engineering Criteria. Prepared for US Department of Transportation, Federal Railroad Administration (2004)

Cambridge Systematics: NGSIM US 101 Data Analysis: Summary Report. Prepared for Federal Highway Administration, Dec 2005

Carbaugh, J., Godbole, D.N., Sengupta, R.: Safety and capacity analysis of automated and manual highway systems. Transp. Res. Part C Emerg. Technol. 6, 69-99 (1998)

Coppola v. Jameson: Iowa 200 NW2d 877 (1972)

Decker v. Wofford: 360 Michigan 644, 104 NW2d 760 (1960)

Dranzo v. Winterhalter: 395 Pa. Super. 578, 577 A.2d 1349 (1990)

Dresner, K., Stone, P.: A multiagent approach to autonomous intersection management. J. Artif. Intell. Res. 31, 591-656 (2008)

Ervin, R.D., Stein J.L., Bogard, S.E., Zachariou, N., Kleinsorge, K.: Active safety conflict modelling (ASCOM) Final Report. UMTRI Report \# UMTRI-97-44. Retrieved 7/15/2017 via: https://deepblue. lib.umich.edu/bitstream/handle/2027.42/1224/94181.0001.001.pdf (1998)

Euler, G.W.: Intelligent vehicle/highway systems: definitions and applications. ITE J. 60, 17-22 (1990)

Fagnant, D., Kockelman, K.: Preparing a Nation for Autonomous Vehicles: Opportunities, Barriers and Policy Recommendations. Eno Foundation, Washington (2014)

Fagnant, D., Kockelman, K.: Dynamic ride-sharing and fleet sizing for a system of shared autonomous vehicles in Austin, Texas. Transportation (2016). doi:10.1007/s11116-016-9729-z

Fambro, D.B., Fitzpatrick, K., Koppa, R.J.: Determination of Stopping Sight Distances. National Cooperative Highway Research Program (NCHRP) Report \#400. National Academy Press, Washington (1997)

Farber, E.I.: Using the REAMACS model to compare the effectiveness of alternative rear-end collision warning algorithms. In: Proceedings of the Fourth Annual Meeting of the Intelligent Vehicle Highway Society of America, 17-20 Apr 1994, Atlanta, GA, pp. 400-407 (1994)

Farber, E.I.: Modelling rear-end collisions and countermeasures. Proceedings of the Application of New Technology to Transport Systems Conference, Melbourne, Australia, pp. 327-340 (1995)

Ferreira, M., d'Orey, P.M.: On the impact of virtual traffic lights on carbon emissions mitigation. IEEE Trans. Intell. Transp. Syst. 13(1), 284-295 (2012)

Florida Department of Highway Safety and Motor Vehicles [DHSMV]: Official Florida Driver License Handbook. www.flhsmv.gov/handbooks/englishdriverhandbook.pdf (2015)

Foulke v. Beogher: 166 Ohio App. 3d 435, 2006-Ohio-1411, 850 N.E.2d 1269 (3d Dist. Marion County 2006) (2006)

Friedrich, B.: The effect of autonomous vehicles on traffic. In: Maurer, M., Christian Gerdes, J., Lenz, B., Winner, H. (eds.) Autonomous Driving: Technical, Legal and Social Aspects. Springer, Berlin (2016)

Fritzsche, H.T.: A model for traffic simulation. Traffic Eng. Control 35, 317-321 (1994)

Galler, B.A., Asher, H.: Vehicle-to-Vehicle Communication for Collision Avoidance and Improved Traffic Flow. IDEA Program, Transportation Research Board. Retrieved 7/15/2017 via: http://ntl.bts.gov/lib/ jpodocs/repts_te/4123.pdf (1995)

Gasser, T.: Traffic control and traffic management in a transportation system with autonomous vehicles. In: Maurer, M., Christian Gerdes, J., Lenz, B., Winner, H. (eds.) Autonomous Driving: Technical, Legal and Social Aspects. Springer, Berlin (2016)

Gipps, P.G.: A Behavioural Car-Following Model for Computer Simulation. Transp. Res. Part B Methodol. 15(2), 105-111 (1981)

Glancy, D.J., Peterson, R.W., Graham, K.F.: A Look at the Legal Environment for Automated Vehicles. National Cooperative Highway Research Program, Legal Research Digest \#69 (2016) 
Goodall, N.J.: Ethical Decision Making During Automated Vehicle Crashes. Transportation Research Record \#2424, pp. 58-65 (2014)

Gucwa, M.: Mobility and energy impacts of automated cars. Presentation at Automated Vehicles Symposium 2014, 15-17 July 2014, San Francisco. Retrieved 7/15/2017 via: http://higherlogicdownload.s3. amazonaws.com/AUVSI/3a47c2f1-97a8-4fb7-8a39-56cba0733145/UploadedImages/documents/pdfs/ 7-16-14\%20AVS\%20presentations/Michael\%20Gucwa.pdf (2014)

International Standards Organization [ISO]: Standard \#22179: Intelligent Transport Systems: Full Speed Range Adaptive Cruise Control (FSRA) Systems-Performance Requirements and Test Procedures. Geneva (2009)

International Standards Organization [ISO]: Standard \#22839: Intelligent Transport Systems: Forward Vehicle Collision Mitigation Systems-Operation, Performance, and Verification Requirements. Geneva (2013)

IVHS America: Strategic Plan for Intelligent Vehicle-Highway Systems in the United States. Report No. IVHS-AMER-92-3. Retrieved 7/15/2017 via: http://ntl.bts.gov/lib/jpodocs/repts_pr/1823.pdf (1992)

Kalra, N., Anderson, J., Wachs, M.: Liability and Regulation of Autonomous Vehicle Technologies. California PATH Research Report UCB-ITS-PRR-2009-28. ISSN 1055-1425 (2009)

Kalra, N., Paddock, S.M.: Driving to Safety: How Many Miles of Driving Would It Take to Demonstrate Autonomous Vehicle Reliability? RAND Corporation, Santa Monica. Retrieved 7/15/2017 via: http:// www.rand.org/pubs/research_reports/RR1478.html (2016)

Kanaris, A., Ioannou, P., Ho, F.S.: Spacing and capacity evaluation for different AHS concepts. In: Ioannou, P.A. (ed.) Automated Highway Systems. Springer, New York (1997)

Khasnabis, S.J., Ellis, T., Baig, M.F.: Legal implications of automated highway systems. Transp. Q. 51, 47-58 (1997)

Kong, Y, Le Vine, S., Liu, X.: Capacity impacts and optimal geometry of automated cars' parking facilities. In: Automated Vehicles Symposium, July 2016, San Francisco, CA (2016)

Laufer, J.: Freeway capacity, saturation flow and the car following behavioural algorithm of the VISSIM microsimulation software. 30th Australasian Transport Research Forum. Retrieved 7/15/2017 via: http://atrf.info/papers/2007/2007_laufer.pdf (2007)

Leibowitz, H.W., Owens, D.A., Tyrrell, R.A.: The assured clear distance ahead rule: implications for nighttime traffic safety and the law. Accid. Anal. Prev. 30(1), 93-99 (1998)

LeValley, D.: Autonomous vehicle liability-application of common carrier liability. Seattle Univ. Law Rev. 36(5), 1-25 (2013)

Le Vine, S., Zolfaghari, A., Polak, J.: Autonomous cars: the tension between occupant-experience and intersection capacity. Transp. Res. Part C Emerg. Technol. 52, 1-14 (2015)

Le Vine, S., Liu, X., Zheng, F., Polak, J.: Automated cars: queue discharge at signalized intersections with 'Assured-Clear-Distance-Ahead' driving strategies. Transp. Res. Part C Emerg. Technol. 62, 35-54 (2016)

Li, Z., Elefteriadou, L., Ranka, S.: Signal control optimization for automated vehicles at isolated signalized intersections. Transp. Res. Part C Emerg. Technol. 49, 1-18 (2014)

Louisiana Farm Bureau Mutual Insurance v. Dunn: 484 So.2d 853 (1986)

Malokin, A., Mokhtarian, P.L., Circella, G.: How do activities conducted while commuting influence mode choice? Testing public transportation advantage and autonomous vehicle scenarios. In: 94th Annual Meeting of the Transportation Research Board, Jan 2016, Washington, DC (2015)

Malone, K.M., Van Arem, B.: Traffic effects of inter-vehicle communication applications in CarTALK 2000. In: 11th World Congress of Intelligent Transportation Systems, Nagoya, Japan, Oct 2004

Mantz v. Continental Western Ins. Co.: 228 Neb. 447, 422 N.W.2d 797 (1988)

Milanes, V., Shladover, S.E.: Handling cut-in vehicles in strings of cooperative adaptive cruise control vehicles. J. Intell. Transp. Syst. 20(2), 178-191 (2016)

Motamedidehkordi, N., Margreiter, M., Benz, T.: Effects of connected highly automated vehicles on the propagation of congested patterns on freeways. In: 95th Annual Meeting of the Transportation Research Board, January 2016, Washington, DC (2016)

Motor Trend: 22 Cars that Stop from $60 \mathrm{MPH}$ in Less Than 100 Feet. Retrieved 7/15/2017 via: www. motortrend.com/features/mt_hot_list/1112_22_cars_that_stop_from_mph_in_less_than_100_feet/ (2011)

Naffky, J.E.: Corpus Juris Secundum: A Contemporary Statement of American Law as Derived from Reported Cases and Legislation, Volume 60A: Motor Vehicles. West, Eagan (2012)

National Highway Traffic Safety Administration [NHTSA]: Final Report for the Methodology study of the Consumer Braking Information Initiative-Phase II. Retrieved 7/15/2017 via: http://icsw.nhtsa.gov/ cars/problems/studies/brakes/Phase2/COVER.html (2000) 
New York State Department of Motor Vehicles [DMV]: Driver's Manual. Retrieved 7/15/2017 via: https:// dmv.ny.gov/brochure/mv21.pdf (2015)

Ohio Revised Code Section 4511.21A. Retrieved 7/15/2017 via: http://codes.ohio.gov/orc/4511.21

Ostrom, E.: Governing the Commons. Cambridge University Press, Cambridge (2015)

Pearson, J.O.: American Law Reports 75, 3d, Automobiles: Sudden Emergency as Exception to Rule Requiring Motorist to Maintain Ability to Stop Within Assured Clear Distance Ahead. American Law Reports, 3rd edn, 75 (2005)

PTV: VISSIM User Manual (2011)

SAE International: Standard J3016: Taxonomy and Definitions for Terms Related to On-Road Motor Vehicle Automated Driving Systems (2014)

Shladover, S.E.: Reasons for operating AHS vehicles in platoons. In: Ioannou, P.A. (ed.) Automated Highway Systems. Plenum, New York (1997)

Skippon, S., Diels, C., Reed, N.: Driving style as a fitness indicator. In: Dorn, L. (ed.) Driver Behaviour and Training, vol. 5, pp. 349-374. Routledge, Abingdon (2012)

Smith, B.W.: Managing Autonomous Transportation Demand. Santa Clara Law Rev. 52(4), 1401-1422 (2012)

Smith, B.W.: Automated Vehicles are Probably Legal in the United States. 1 Tex. A\&M L. Rev. 411 (2014). doi: $10.2139 / \mathrm{ssrn} .2303904$

Speiser, K., Treleaven, K.B., Zhang, R., Frazzoli, E., Morton, D., Pavone, M.: Toward a Systematic Approach to the Design and Evaluation of Automated Mobility-on-Demand Systems: A Case Study in Singapore. Springer Lecture Notes in Mobility: Road Vehicle Automation, pp. 1-17. Springer, Berlin (2014)

Stevens, W.B.: Societal and institutional aspects of AHS deployment. In: Ioannou, P.A. (ed.) Automated Highway Systems. Plenum, New York (1997)

Texas Department of Public Safety [DPS]: Texas Driver Handbook, Revised January 2016. Retrieved 7/15/ 2017 via: https://www.txdps.state.tx.us/internetforms/Forms/DL-7.pdf (2014)

Texas Transportation Code, Title 7, Sect. 545.062. Retrieved 7/15/2017 via: http://www.statutes.legis.state. tx.us/Docs/TN/htm/TN.545.htm

Transportation Research Board [TRB]: Highway Capacity Manual: 2010 Edition. Washington, DC (2010)

Transportation Research Board [TRB]: 75 Years of the Fundamental Diagram for Traffic Flow Theory. Transportation Research Circular \#E-C149. http://www.onlinepubs.trb.org/onlinepubs/circulars/ec149. pdf (2011)

Transportation Research Board [TRB]: The 2nd Strategic Highway Research Program Naturalistic Driving Study Dataset. Available from the SHRP2 NDS InSight Data Dissemination web site: https://insight. shrp2nds.us. Retrieved 7/15/2017 (2013)

United States v. Carroll Towing: 159 F.2d 169, 2nd Cir., January 9, 1947

Urmson, C.P., Dolgov, D.A., Nemec, P.: Driving Pattern Recognition and Safety Control. U.S. Patent \#US8965621 B1 (2015)

U.S. Department of Transportation [USDOT]: Next Generation SIMulation: U.S. Highway 101 Dataset Fact Sheet. Retrieved 7/15/2017 via: http://www.fhwa.dot.gov/publications/research/operations/07030/ index.cfm (2016)

Vander Werf, J., Shladover, S.E., Miller, M., Kourjanskaia, N.: Effects of Adaptive Cruise Control Systems on Highway Traffic Flow Capacity. Transportation Research Record \#1800 (2002)

Van Arem, B., van Driel, C.J.G., Visser, R.: The impact of cooperative adaptive cruise control on trafficflow characteristics. IEEE Trans. Intell. Transp. Syst. 7(4), 429-436 (2006)

Wadud, Z., MacKenzie, D., Leiby, P.: Help or hindrance: the travel, energy and carbon impacts of highly automated vehicles. Transp. Res. Part A Policy Pract. 86, 1-18 (2016)

Wiedemann, R.: Simulation des Strassenverkehrsflusses. University Karlsruhe (1974) (in German)

Yang, Q., Koutsopoulos, H.N.: A microscopic traffic simulator for evaluation of dynamic traffic management systems. Transp. Res. Part C Emerg. Technol. 4, 113-129 (1996)

Yeo, H., Skarbadonis, A.: Understanding stop-and-go traffic in view of asymmetric traffic theory. In: Lam, W.H.K., Wong, H., Lo, H.K. (eds.) Transportation and Traffic Theory 2009: Golden Jubilee: Papers selected for presentation at ISTTT18. Springer, Berlin (2009)

Zhang, W., Guhathakurta, S., Fang, J., Zhang, G.: Exploring the impact of shared autonomous vehicles on urban parking demand: an agent-based simulation approach. Sustain. Cities Soc. 19, 34-45 (2015)

Zhou, M., Qu, X.: Modelling the effect of cooperative autonomous vehicles on freeway merging. In: 95th Annual Meeting of the Transportation Research Board, January 2016, Washington, DC (2016) 
Zmud, J. Sener, I., Wagner, J.: Consumer Acceptance and Travel Behavior Impacts of Automated Vehicles. Texas A\&M Transportation Institute, PRC 15-49 F. January 2016. Retrieved 7/15/2017 via: http:// d2dt15nnlpfr0r.cloudfront.net/tti.tamu.edu/documents/PRC-15-49-F.pdf (2016)

Scott Le Vine is a Visiting Professor at Southwest Jiaotong University, an Assistant Professor (Urban Planning) at SUNY New Paltz, and a Research Associate at Imperial College London.

You Kong is a doctoral candidate in the School of Transportation and Logistics at Southwest Jiaotong University.

Xiaobo Liu is Dean of the School of Transportation and Logistics at Southwest Jiaotong University.

John Polak is Professor of Travel Demand and Director of the Urban Systems Laboratory at Imperial College London. 